\title{
Genetic Types and Main Control Factors of Microfractures in Tight Oil Reservoirs of Jimsar Sag
}

\author{
Xiangye Kong $\mathbb{D}^{1,2}$ Jianhui Zeng ${ }^{1},{ }^{1,2}$ Xianfeng Tan $\left(\mathbb{D},{ }^{3}\right.$ Haowei Yuan, ${ }^{1,2}$ Dan Liu, ${ }^{4}$ \\ Qun Luo, ${ }^{5}$ Qianyou Wang, ${ }^{6}$ and Rusi $\mathrm{Zuo}^{7}$ \\ ${ }^{1}$ College of Geosciences, China University of Petroleum, Beijing 102249, China \\ ${ }^{2}$ State Key Laboratory of Petroleum Resources and Prospecting, China University of Petroleum, Beijing 102249, China \\ ${ }^{3}$ College of Petroleum and Gas Engineering, Chongqing University of Science and Technology, Chongqing 401331, China \\ ${ }^{4}$ Institute of Exploration Techniques, CAGS, Langfang Hebei 065000, China \\ ${ }^{5}$ Unconventional Natural Gas Institute, China University of Petroleum, Beijing 102249, China \\ ${ }^{6}$ Department of Earth, Ocean and Ecological Sciences, University of Liverpool, Liverpool L69 3GP, UK \\ ${ }^{7}$ State Key Laboratory of Marine Geology, Tongji University, Shanghai 200092, China
}

Correspondence should be addressed to Jianhui Zeng; zengjh@cup.edu.cn and Xianfeng Tan; xianfengtan8299@163.com

Received 28 January 2021; Accepted 1 July 2021; Published 24 July 2021

Academic Editor: Paolo Madonia

Copyright (C) 2021 Xiangye Kong et al. This is an open access article distributed under the Creative Commons Attribution License, which permits unrestricted use, distribution, and reproduction in any medium, provided the original work is properly cited.

\begin{abstract}
Microfractures are key for migrating and aggregating hydrocarbon source rocks and fracturing oil-gas exploitation in tight reservoirs. In this study, rock samples from the Lucaogou Formation tight reservoirs in Xinjiang, China, were studied using multidisciplinary techniques to investigate the genetic types and main control factors of microfractures. Results indicated that the Lucaogou Formation mainly developed diagenetic microfractures followed by tectonic microfractures, with slight formations of granular microfractures. These observations were used to clarify the relationship between the development of microfractures and the pore fluid content, lithology, mineral composition, and stratum thickness. A higher pore fluid content corresponded to a lower compressive strength of the rocks and a larger ring count, resulting in a higher probability of failure and microfracture formation. Tight reservoirs containing more quartz and carbonate minerals were found to develop more microfractures. Quartz grains showed fractures at the margins under stress, which increased the pore permeability of rocks. Carbonate minerals tended to form microfractures owing to corrosion. Microfracture formation mechanisms differed depending on lithology, and microfractures were found to develop most in dolomite and dolomitic siltstones and least in mudstone. Muddy rocks developed fewer tectonic fractures because they can easily absorb stress and undergo plastic deformation. Within a certain stratum thickness range, the average single-well fracture space and stratum thickness showed positive correlations. Moreover, the fracture space increased and the fracture density decreased as the stratum thickness increased. When the stratum thickness was less than $2.5 \mathrm{~m}$, the fracture space increased linearly with the stratum thickness, and when the stratum thickness was greater than $2.5 \mathrm{~m}$, the fracture space remained constant. This study will provide an essential scientific basis for enhancing tight oil recovery.
\end{abstract}

\section{Introduction}

Natural fractures are widespread in tight reservoirs [1-4]. Microfractures affect not only the migration and accumulation of oil and gas but also the outcome of oil-gas development. However, existing research on microfractures is not comprehensive [5]. The formation, development, and connection of microfractures provide channels for the migration and aggregation of oil and gas in tight reservoirs [6-9]. Microfractures are important spaces in tight reservoirs that gradually form large-scale and complex fracture networks [10-13]. Microfractures are defined as fractures with an opening of $<100 \mu \mathrm{m}$ and are unrecognisable on imaging logs or core samples but can be observed using microscopy (e.g., casting thin sections or scanning electron microscopy (SEM)); they are predominantly diagenetic or corroded fractures $[14,15]$. 
Fractures with an opening between $100 \mathrm{~nm}$ and $1 \mathrm{~mm}$ are defined as microfractures, and fractures with a width of $<1 \mu \mathrm{m}$ are called supermicrofractures $[16,17]$. The formation of microfractures is affected by tectonic movements, sedimentary environment, burying conditions, fluid properties, and other factors [18]. The genetic types of microfractures are defined by tectogenesis, which is related to diagenesis. When tectonic loading is applied externally, a rock can fracture and eventually fail along faults. Conversely, internal stresses may be related to increased fluid pressure inside the rock due to the dehydration of clays. The joints of microfractures can be analysed via the stress analysis of a rose diagram [19]. During diagenesis, sediments are affected by compacted shrinkage, mineral cementation, metasomatism, and recrystallisation. These occurrences induce the contraction and expansion of strata and the recombination and conversion of minerals. Such changes are accompanied by the development of microfractures to different degrees [20]. Microfracture formation is largely affected by early-stage compaction and late-stage corrosion. Corroded carbonate minerals can easily form corroded fractures, which normally develop along cleavages. Compacted rocks often develop compressed fractures [21-23]. The reservoirs in the Upper Palaeozoic Shihezi Formation were derived from diverse sources and contained various sediments, resulting in severe longitudinal lithological heterogeneity [21]. Diagenesis induces changes in lithological composition and significantly affects the physical properties of reservoirs. Diagenesis also differs considerably among strata, which can develop diverse and structurally complex pores. Microfractures are believed to be the main channels of reservoir seepage, and the distributive laws and developmental characteristics of microfractures are controlled by diagenesis and lithology [24].

Microfractures are detected and evaluated mainly using mercury intrusions, image analysis, imaging logs, and magnetic logs of core data. Considering that microfracture control mechanisms depend on the reservoir lithology, diagenesis, and pore type, a specific lithology can be recognised for any horizon. Thereafter, valid porosity and permeability evaluation models can be established based on lithology and horizon constraints. Wang and Rahman developed a microfracture evaluation model and an identification method to analyse more than 70 wells [25]. The relative error of permeability using logging evaluations was less than $10 \%$, and many new active gas layers were observed [26]. Overall, among wells with a gas production rate exceeding the lower economic limit $\left(3 \times 10^{4} \mathrm{~m}^{3} / \mathrm{d}\right)$, more than $90 \%$ developed microfractures [27]. The wells with high single-well gas production rates developed high-permeability microfractures, thus validating the results of the model [24, 25].

The Lucaogou Formation in the Jimsar Sag of Junggar Basin in Xinjiang, China, is typical continental tight oil strata showing developed tight oil reservoirs with highquality hydrocarbon source rocks, featuring active oil-gas exploitation, large oil-gas reserves, and significant exploration potential $[7,28,29]$. The Lucaogou Formation is one of China's most important tight oil strata. Since 2010, commercial oil production has been realised in several wells in the Jimsar Sag (including wells J23, J25, and
J30), representing a breakthrough in tight oil production in the southeast Junggar Basin [30, 31]. The Lucaogou Formation strata mainly comprise carbonate rocks, mudstone, and powder-fine sandstone [29]. Previous works in this region were mainly focused on the macroscale, such as the geological structure and sedimentary environment; however, little research has been conducted at the microscale. The role of fractures in reservoirs of Jimsar Sag has also been noted [31].

Hence, this study focused on qualitatively and quantitatively identifying microfractures in the Lucaogou Formation to clarify the causes and basic parameters of microfracture development. The developmental characteristics and control factors of the microfractures were elucidated, and the influence of microfracture development on reservoir properties was determined.

\section{Geological Settings}

The Junggar Basin is the second-largest basin in China. It is rich in tight oil reservoirs and shows high potential for exploration and development. It belongs to the Ural-Mongolia Orogenic Belt, which is surrounded by multiple orogenic belts, such as the Altai and Bogda Mountains. Its north is bounded by the Shaqi Uplift and Jimsar Sag, and its south is bounded by the Houbaozi Fault. Its west is bounded by the Xidi Fault and Beisantai Uplift, and its east transitions from a slope to the Guxi Uplift (Figures 1 and 2). The Junggar Basin is surrounded by several other basins such as Tuha, Erie, and Santanghu Basins [32-35]. The Junggar Basin initially formed during the Hercynian activity period. In the late Early Permian, the Bogda Trough at the south margin of the basin was closing for orogenesis. In the late Middle Permian, the Lucaogou Formation started experiencing lacustrine facies sedimentation, forming the main hydrocarbon source rocks in this region. In the Late Triassic, the Indo-China Movement occurred, leading to severe uplifting of the Guxi Uplift and the Permian differential corrosion. During the Yanshan Movement, frequent and severe tectonic movements occurred inside the Junggar Basin, inducing gentle uplift in the southeast. The Himalayan Movement formed from the Neogene to Quaternary, leading to the rest of the basin evolution [32, 34, 36, 37].

The internal tectogenesis of Jimsar Sag is relatively stable, and the inner strata of the basin are complete, with maximum sedimentation thickness of $5000 \mathrm{~m}$. The stratigraphic framework of Jimsar was formed after the Himalayan orogeny. The strata are mostly in conformable contact, and the deficient part comprises the Huangshanjie Formation, Jurassic Kelazha Formation, and Triassic Haojiagou Formation. The Lucaogou Formation (P $2 l$ ) originates from the Permian and is beneath the Wutonggou Formation (P3wt) and above the Jiangjunmiao Formation (P2j). Full-well cores were collected from well J174 in the basin. Based on its lithology, magnetic logs, electric data, and systematic analysis, the Lucaogou Formation can be divided into two segments (P2l2 and P2l1) and four layers (P2l21, P2l22, P2l11, and P2l12) [38]. 


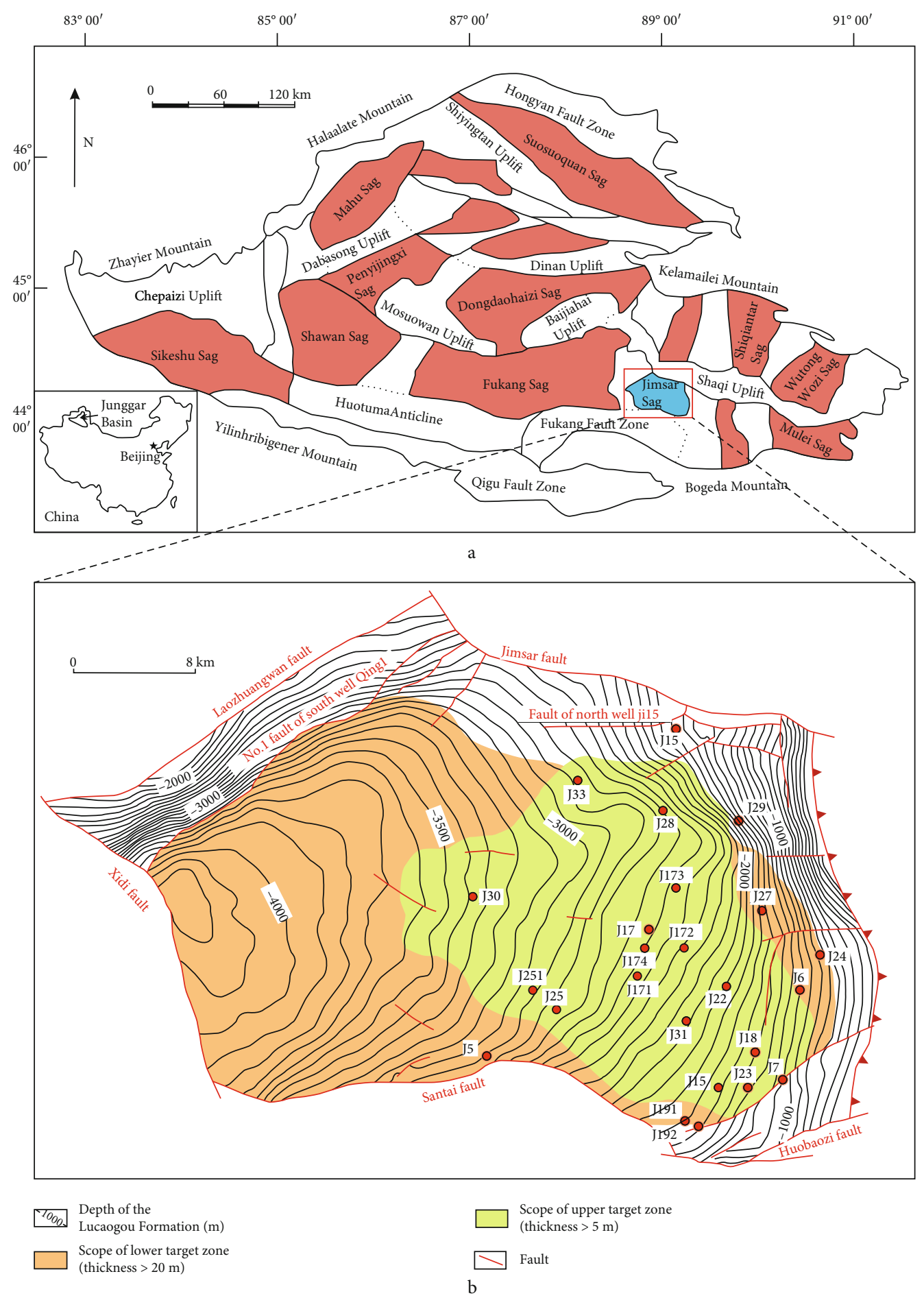

FIGURE 1: Structural division of the Junggar Basin.

The Lucaogou Formation was affected by mechanical sedimentation, thus comprising hybrid sedimentary rocks deposited in salty lakes. During the Penecontemporary period, rocks in this area experienced severe dolomitisation; hence, dolomites normally developed with micrite and microcrystalline structures, with small grain-sized detritus enriched with carbonate rocks, mudstone, and powder-fine sandstones that were mostly interlayered. The rock types mainly include mudstone, fine siltstone, and carbonate rocks. The fine siltstone mainly includes dololithite fine siltstone, lithic feldspar fine siltstone, and dolomitic fine siltstone. The carbonate rocks mainly include muddy microlite dolomite, fine sandy dolomite, and sand detritus dolomite. The carbonate rocks are dominated by dolomitic rocks and limestone, which comprise up to $74.15 \%$ in some areas. Thus, the Lucaogou Formation is generally rich in carbonate minerals 


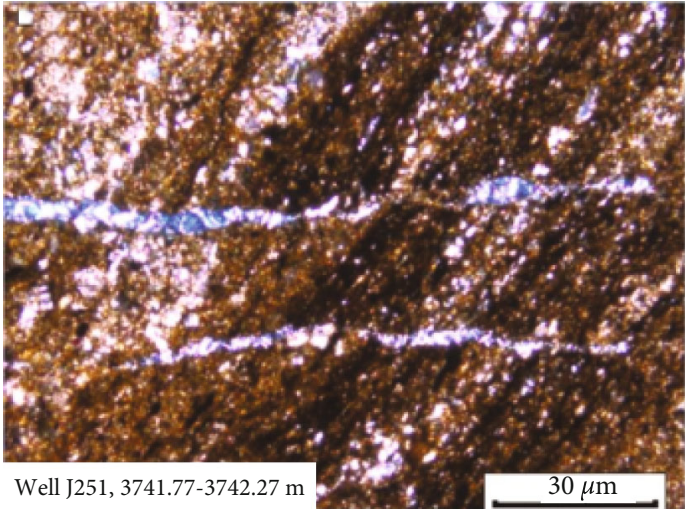

(a)

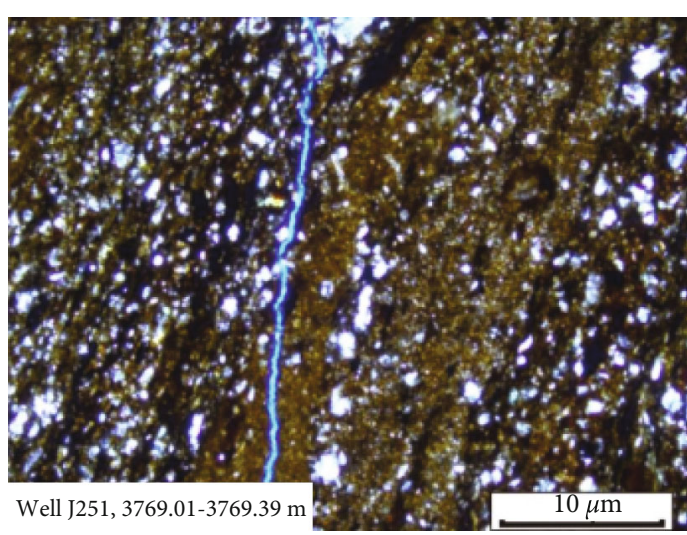

(b)

Figure 2: Typical microfractures with a high opening in casting thin section of the Lucaogou Formation in the Jimsar Sag: (a) well J251, 3741.77-3742.27 m; (b) well J251, 3769.01-3769.39 m.

and is highly brittle, making it suitable for large-scale exploitation [39]. The Lucaogou Formation is well developed with microfractures. The tight sandstone in the study area is rich in clay but has fewer authigenic minerals than the crystals of common sandstone reservoirs. In addition to autogenetic causes (including the cause of alteration), terrigenous detritus sedimentation is observed.

\section{Methodology}

72 rock samples were collected from 22 exploration wells in the Middle Permian of the Lucaogou Formation. These samples included grey dolerite, feldspathic, dolomitic lithic sandstone, and dolomitic mudstone. Before the tests, the core samples were washed with a mixture of trichloromethane and alcohol to eliminate residual oil and then dried at $115^{\circ} \mathrm{C}$ for $26 \mathrm{~h}$ under vacuum. Each core sample was drilled to a size with a diameter and length of 2.54 and $5.00 \mathrm{~cm}$, respectively. The following methods were adopted for investigations: casting thin sections, SEM, acoustic emission (AE), and nuclear magnetic resonance (NMR). Casting thin sections and SEM can clearly visualise the morphology, occurrence, filling, and peripheral mineral contact of microfracture development. $\mathrm{AE}$ and NMR can clarify the structural characteristics of rocks.

3.1. Microscopy. The casting thin section and scanning electron microscopy experiments were completed in the State Key Laboratory of Petroleum Resources and Exploration, China University of Petroleum (Beijing). The samples were detected by ZEISS Merlin and GeminiSEM instruments. Casting thin sections were used to study the quantity, type, and distribution of pores. A staining resin or liquid glue was perfused into the rock pores under vacuum. The resin or glue solidified at a certain temperature and pressure, and the rock was then ground into sections, which were used to observe pore structures under polarisation [40]. Figure 2(a) shows a cast thin section with two microfractures with an opening of $2-5 \mu \mathrm{m}$. The microfractures exhibit an oblique crossing strike with bedding; hence, they appear to be tectonic fractures that mainly formed because of external forces.
Figure 2(b) shows a cast thin section with only one microfracture with an opening of $1-3 \mu \mathrm{m}$ that developed along the layers. Thus, it appears to be a bedding fracture. SEM is a comprehensive analyser that affords high-resolution images and can be used to observe microfractures up to several nanometres [41, 42]. More than 200 SEM images and cast thin sections were acquired from 10 wells in the study area, including J174, J251, J36, and J172. Secondary microfractures were mainly observed, with only a few original intergranular pores, and they mostly developed along the layers. Figure 3 shows that the fractures developed inside minerals or along mineral margins with complex arrangements.

3.2. Acoustic Emissions. The rock triaxial acoustic emission experiment was completed in the Laboratory of Rock Mechanics, China University of Petroleum (Beijing). The test loading was carried out by the MTS 815 rock mechanics test system of MTS Company, and the acoustic emission acquisition was carried out by the PCI-II acoustic emission monitoring system of PAC Company. The $\mathrm{AE}$ technique visualises the changes in internal materials in rocks using $\mathrm{AE}$ events. $\mathrm{AE}$ events record the $\mathrm{AE}$ induced in the rocks owing to changes resulting from external forces. An $\mathrm{AE}$ experiment was performed, and the variations in the energy count and $\mathrm{AE}$ count were used to analyse the fracture process. The fracture process occurs in three stages. In the crack concentration stage, the initial microfractures gradually grow under external forces; thus, the AE curve manifests as a smooth rising line. In the fracture expansion stage, the expansion is intermittent; hence, numerous fractures are formed, showing a zigzag curve. In the broken damage stage, the rocks suddenly experience instantaneous failure $[43,44]$. Research on the Yanchang Formation in the Ordos Basin showed that microfractures are formed when the external force imposed on a rock reaches the fracturing intensity. Hence, AE events can be measured using an $\mathrm{AE}$ curve to indicate the exact location of microfractures [45-47]. The experiments verified that after passing Caesar's phenomenon, the first small-scale microrupture period is the microfracture formation period. As shown in Figure 4, the cumulative number of AE events 


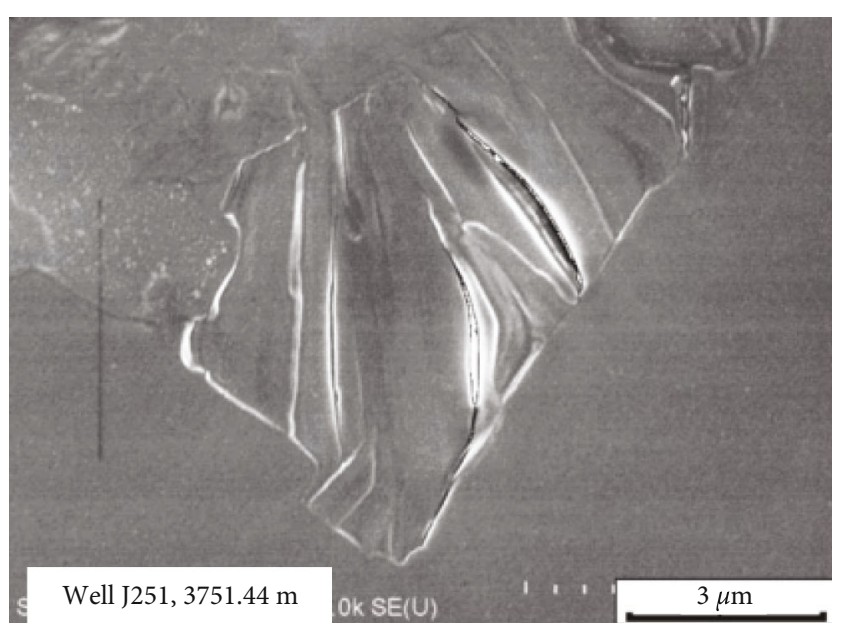

(a)

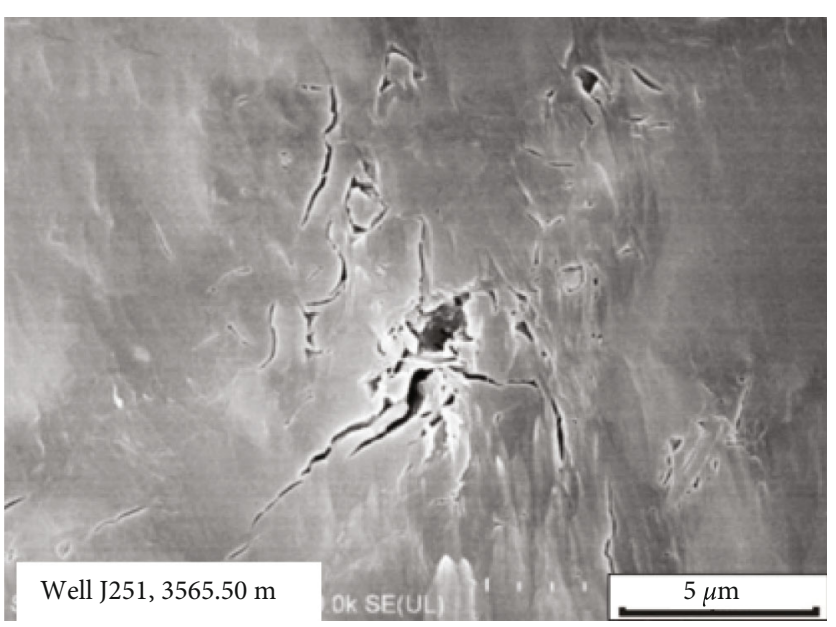

(b)

Figure 3: Typical microfractures are developed inside minerals or along mineral margins in microscopic scale of the Lucaogou Formation in the Jimsar Sag: (a) well J251, 3751.44 m; (b) well J251, $3565.5 \mathrm{~m}$.

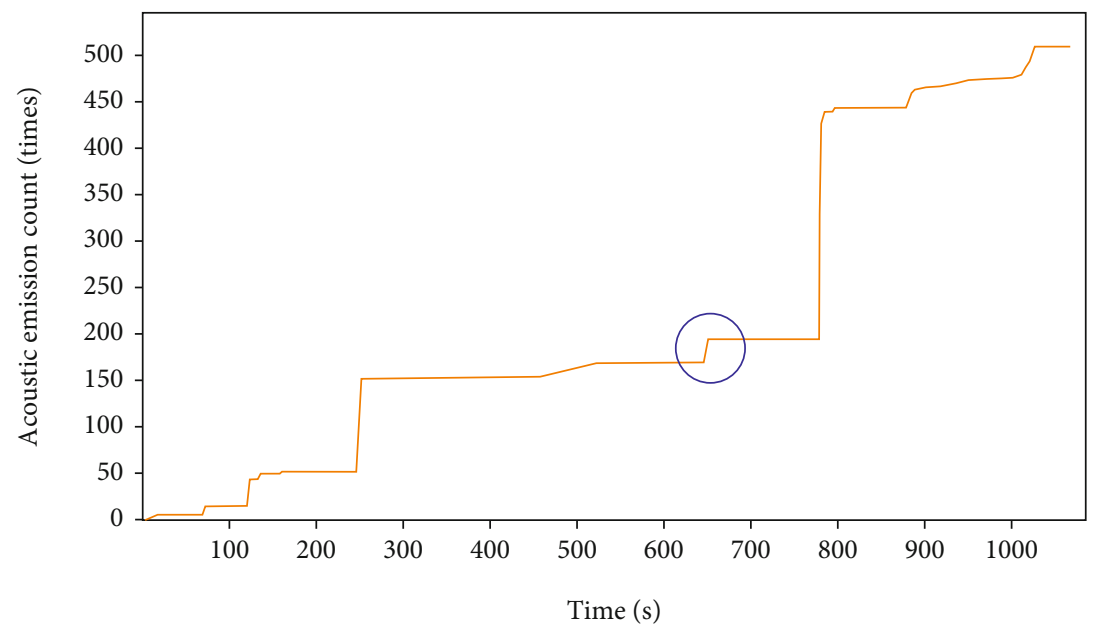

(a)

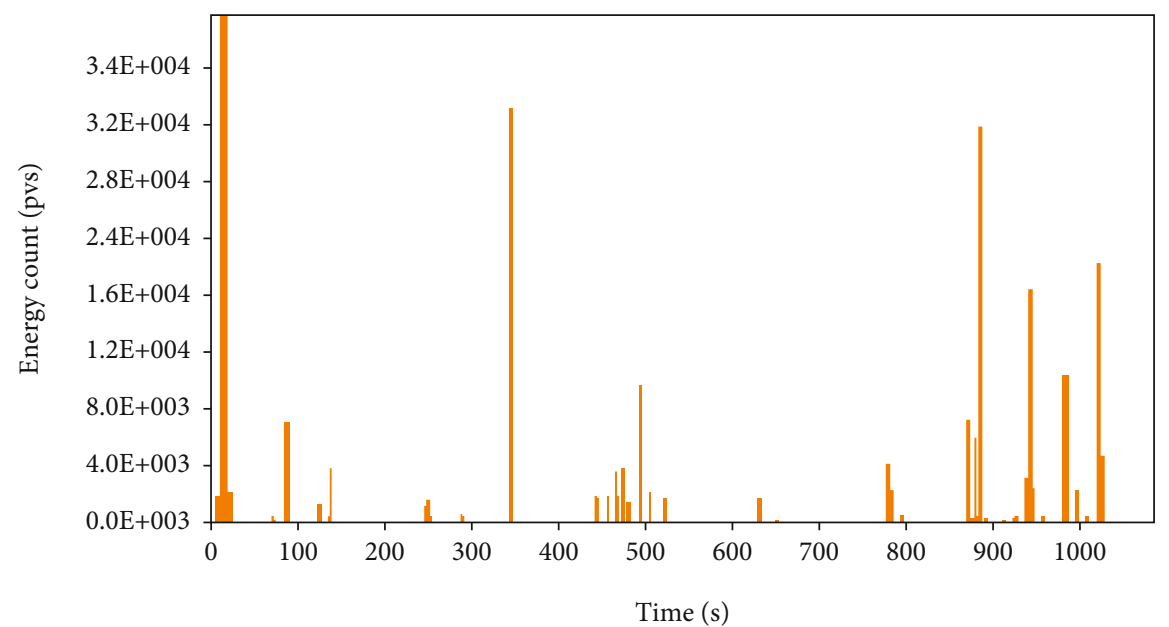

(b)

FIgURE 4: The acoustic emission curve of the three-axis compression process: (a) curve of acoustic emission count with time; (b) curve of energy count with time. 


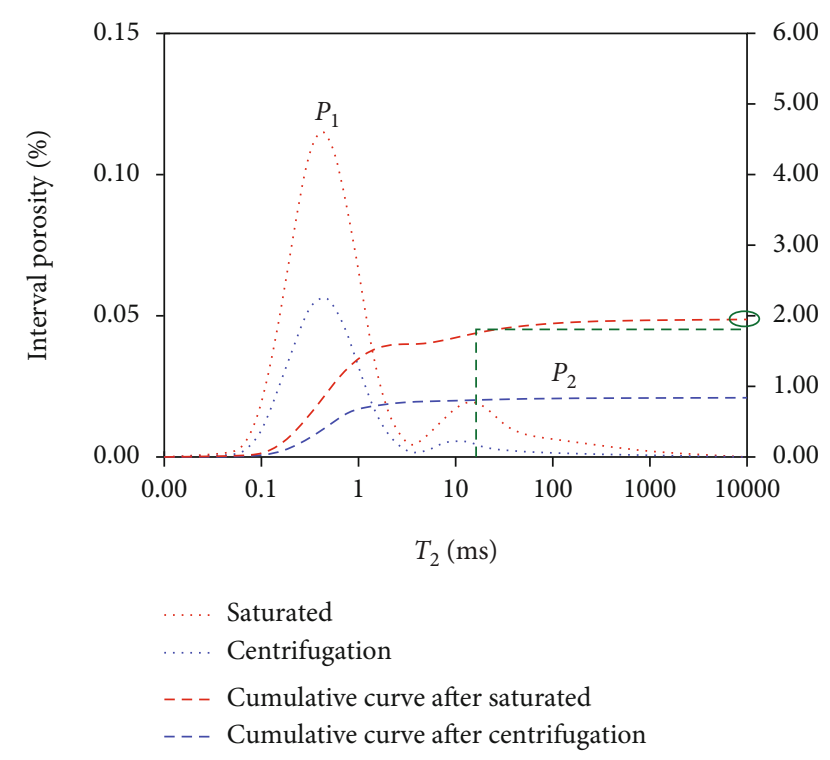

FIGURE 5: NMR $T_{2}$ features (saturated curve, centrifugation, cumulative curve after saturation, and cumulative curve after centrifugation) of samples from well 174 .

on the $\mathrm{AE}$ curve was used to determine the number of microfractures [48].

3.3. Nuclear Magnetic Resonance. The NMR $T_{2}$ distributions were measured at $20^{\circ} \mathrm{C}$ using a $2 \mathrm{MHz}$ Suzhou Niumag Analytical Instrument at State Key Laboratory of Petroleum Resources and Prospecting. The rock samples were subjected to NMR tests. The area of the NMR $T_{2}$ spectrum indicates the variation in the pore structure and is proportional to the pore fluid concentration in rocks. Herein, the relaxation time was used to observe the pore size distributions of rock samples. When the relaxation time is long, the corresponding $T_{2}$ spectrum indicates the pore volume of relatively large-sized pores. The microfractures of tight sandstone can be studied via the qualitative and quantitative analyses of NMR data [49]. Figure 5 shows that a new peak appeared in the $T_{2}$ spectra under the saturated status, and the original peak moved leftwards to form a double peak. These results indicate the formation of numerous microfractures that contributed to the porosity of the rock samples. When the NMR $T_{2}$ spectra were observed in the irreducible water state, the right-side peak disappeared. Considering that fractures easily broke in the centrifugal status, the right-side peak can be considered to indicate microfracture formation. The fracture/microfracture percentage ratio can be defined as the sum of $T_{2}$ spectral amplitudes with a relaxation time $T_{2}$ of $>10 \mathrm{~ms}$ divided by the total number of $T_{2}$ spectral amplitudes [50, 51]. Because microfractures can easily break during centrifugation and NMR analysis, the fracture/microfracture percentage ratio was used to represent the developing degree of microfractures in each sample.

3.4. Experimental Procedure. First, porosity experiments based on helium were performed to select samples with consistent lithology and relatively large porosity. The sam-

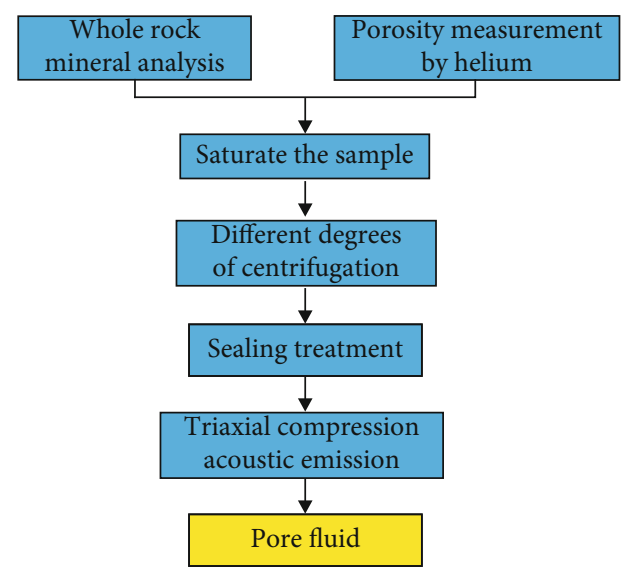

Figure 6: Experimental flowsheet on fluid saturation correlation between microfractures and pores.

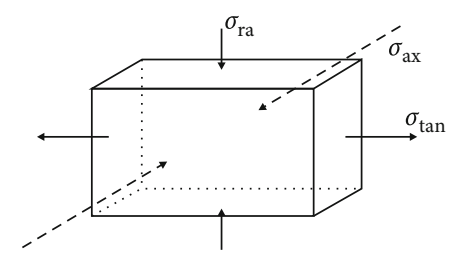

FIgURE 7: Three-dimensional stress diagram.

ples were saturated to $100 \%$ using a saturation metre and then saturated to different degrees by reconfiguration in centrifugation experiments. Then, the samples were sealed. Finally, triaxial compression experiments were performed, and $\mathrm{AE}$ was used to monitor fracture formation. Figure 6 shows the relationship between fractures and the pore fluid concentration.

Centrifuging is widely used to separate standard rock samples into high, medium, and low permeability. The centrifugal pressure must satisfy

$$
P=1.097 \times 9 L\left(R_{\mathrm{e}}-\frac{L}{2}\right) n^{2},
$$

where $L$ is the rock length (mm), $R_{\mathrm{e}}$ is the epitrochoid radius $(\mathrm{mm})$, and $n$ is the rotating speed at the head of the centrifuge.

Triaxial compression experiments were performed, where the three-dimensional stress states of rock samples were simulated (Figure 7) to measure the maximum and minimum principal stresses. Then, the compressive strength, internal friction angle, and cohesion of the rocks were measured using multiple tests.

Three groups of rocks were placed in a saturation metre. Because all rock samples were tight sandstone, the static pressure for saturation was set to $20 \mathrm{MPa}$. Four rock samples (two samples per group) were placed in an LD5-10B centrifuge and centrifuged at 8000 rotations. After $1 \mathrm{~h}$, the rock samples were removed. Then, one sample from each group was selected and placed inside the centrifuge again. When the lithology is consistent and the centrifugation time is the 
TABLE 1: Parameters involved in the acoustic emission counting for the Lucaogou Formation tight sandstones in the Jimsar Sag, Junggar Basin.

\begin{tabular}{|c|c|c|c|}
\hline Group & $\begin{array}{l}\text { No. of } \\
\text { core }\end{array}$ & $\begin{array}{c}\text { Condition of water } \\
\text { saturation }(\%)\end{array}$ & $\begin{array}{l}\text { Acoustic emission } \\
\text { counting }\end{array}$ \\
\hline \multirow{4}{*}{ G1 } & J174-1 & 0 & 50 \\
\hline & J174-2 & 30 & 65 \\
\hline & J174-3 & 80 & 100 \\
\hline & J174-4 & 100 & 166 \\
\hline \multirow{4}{*}{ G2 } & $\mathrm{J} 22-1$ & 0 & 53 \\
\hline & $\mathrm{J} 22-2$ & 30 & 74 \\
\hline & $\mathrm{J} 22-3$ & 90 & 101 \\
\hline & $\mathrm{J} 22-4$ & 100 & 169 \\
\hline \multirow{4}{*}{ G3 } & J36-1 & 0 & 56 \\
\hline & $\mathrm{J} 36-2$ & 30 & 65 \\
\hline & $\mathrm{J} 36-3$ & 70 & 107 \\
\hline & J36-4 & 100 & 170 \\
\hline
\end{tabular}

same, the rock samples must show a consistent decrease in water content. The above steps were repeated successively. The centrifuged samples were then immediately sealed for the triaxial experiment. The rock samples were set in an antioil and antipressure plastic set that was custom-made and softened using blowing so that the samples tightly clung to the set. The set was installed according to experimental requirements. Then, the sensor was adjusted and slowly compressed. Simultaneously, the AE analyser was started. Thereafter, the corresponding rock mechanical parameters were determined. The $\mathrm{AE}$ curves were used to record the number of $\mathrm{AE}$ rings upon microfracture formation (i.e., number of AE events) (Table 1).

The main factors that affect the formation of microfractures in rocks are the contents of fragile minerals and carbonates. In this experiment, the quantitative relationship between microfractures and mineral composition was mainly studied from two aspects. First, several rock samples rich in carbonates were selected according to their lithological data and physical properties. Then, the rocks were fractured in triaxial compression experiments to form microfractures. Samples showing evident microfractures in the NMR $T_{2}$ spectrum were selected and used to analyse the quantitative relationship between the mineral composition and microfractures (Figure 8).

The main form of NMR applied to tight sandstone is usually the transverse relaxation time $T_{2}$. Under rapid diffusion conditions, the relaxation time $T_{2 a}$ of a pore fluid can be approximated as

$$
\frac{1}{T_{2 a}}=\frac{1}{T_{2 b}}+\rho_{2} \frac{S}{V}
$$

where $T_{2 b}$ is the inherent relaxation time (ms) of pore fluid in a rock, $\rho_{2}$ is the surface relaxation rate in a fluid-containing pore $(\mu \mathrm{m} / \mathrm{ms})$, and $S / V$ is the ratio of surface area to volume

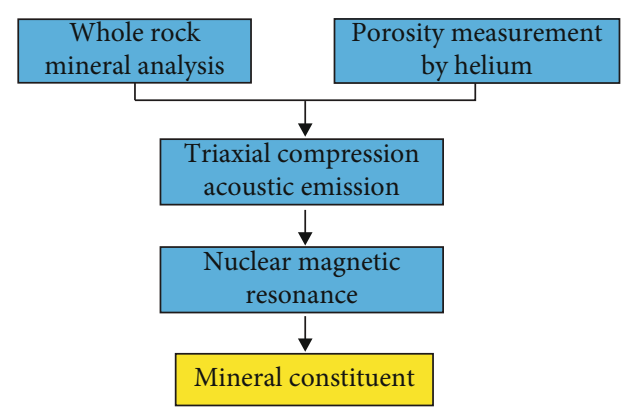

FIgURE 8: The experimental flow chart of correlation between microfractures and mineral composition.

of the corresponding pore and is inversely proportional to the pore size:

$$
\frac{S}{V}=\frac{F_{s}}{r}
$$

where $F_{S}$ is the pore shape factor and $r$ is the pore radius. When the pore fluid is water or light oil, the long inherent relaxation time leads to

$$
\frac{1}{T_{2 a}}=\rho_{2} \frac{S}{V}
$$

For the same rock sample, the relaxation rate $\rho_{2}$ and pore shape factor $F_{S}$ can be approximated as constants. Hence, the $T_{2}$ spectra can be used to determine the distribution of rock pores because rocks with longer relaxation times correspond to larger fractures, and vice versa $[52,53]$.

Before the experiments, tight sandstone samples were ground and parallelled. The samples were dried in a thermostatic drying chamber at $60^{\circ} \mathrm{C}$ for approximately $24 \mathrm{~h}$ until the weight no longer changed. Then, the basic parameters of the samples were measured at a peripheral pressure of $900 \mathrm{psi}$, air pressure of $400 \mathrm{psi}$, and pulse attenuation of PDP-200. To further clarify the mineral composition, the rock samples were tested in terms of the total organic carbon, kerogen ultimate analysis, whole-rock mineral X-ray diffraction, and organic matter macerals.

\section{Genetic Types of Microfractures}

Microfracture formation was primarily attributed to the tectonic stress field during rock diagenesis $[54,55]$. Given the small openings and invisibility of microfractures, microscopy (i.e., casting thin sections and SEM) was used to observe their developmental characteristics to explore genetic types. Microfractures were generally well developed in the Lucaogou Formation with complex genetic types, including tectonic fractures, bedding fractures, intragranular fractures, marginal fractures, corroded fractures, diagenetic contraction fractures, and organic hydrocarbon-producing high-pressure fractures. These microfractures can be broadly classified as tectonic (i.e., directional), granular, or diagenetic based on their genetic types. 


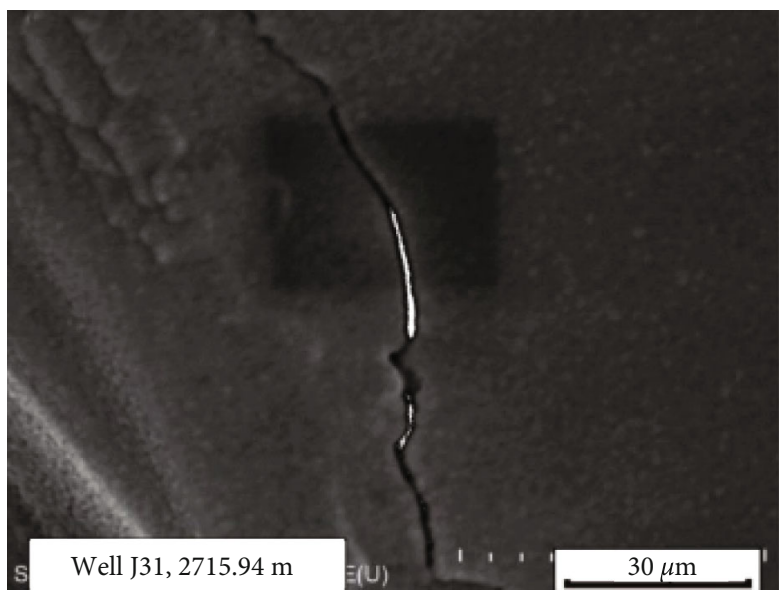

(a)

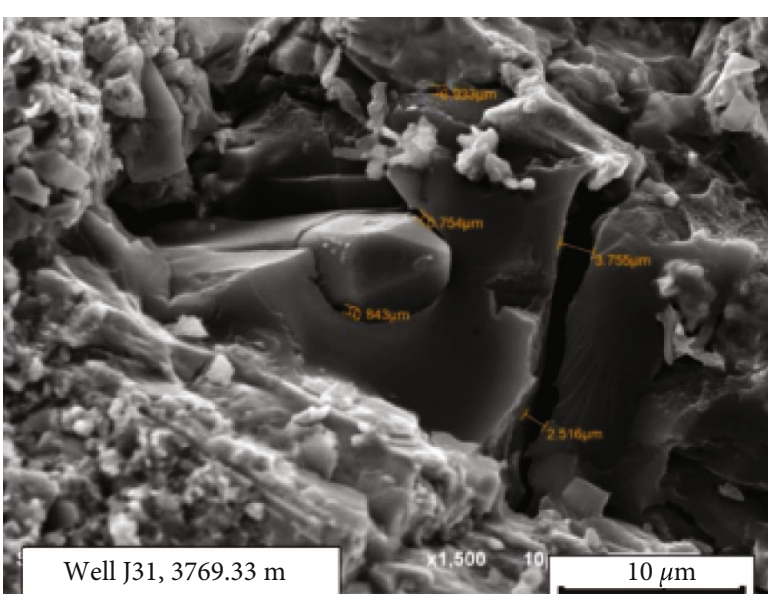

(b)

FIgURE 9: Tectonic-breaking microfractures in microscopic scale of the Lucaogou Formation in the Jimsar Sag: (a) well J31, 2715.94 m; (b) well J31, $3769.33 \mathrm{~m}$.

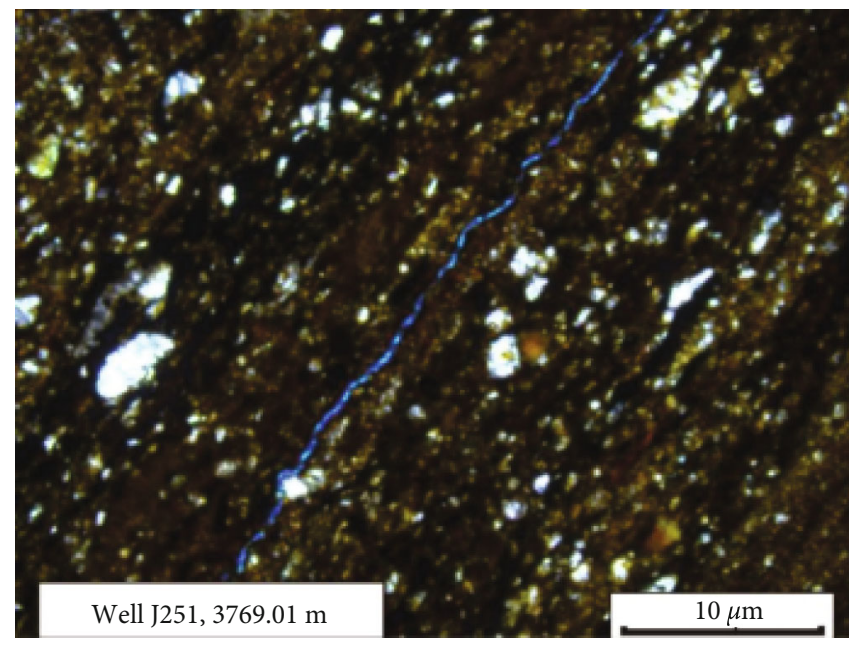

(a)

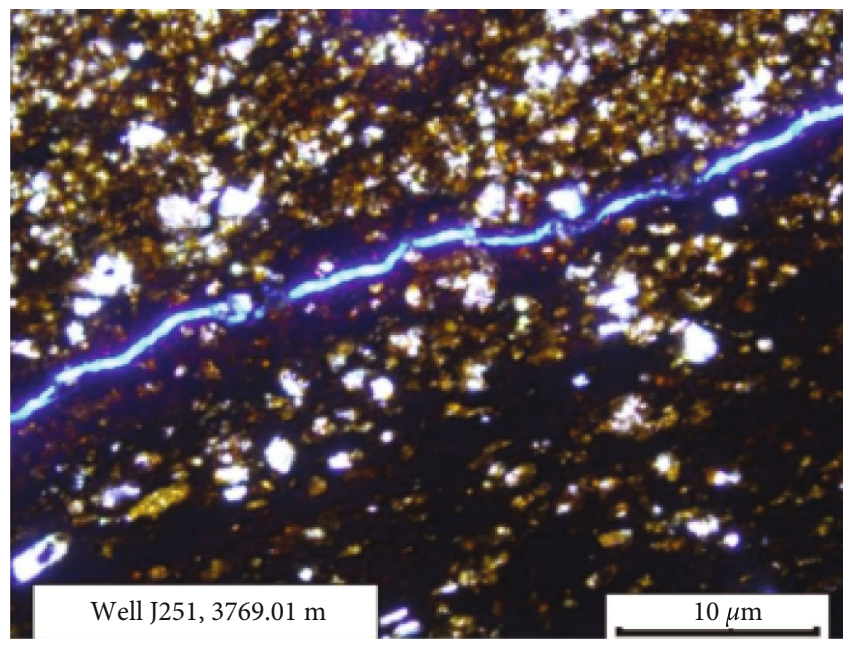

(b)

Figure 10: Bedding fractures in microscopic scale of the Lucaogou Formation in the Jimsar Sag: (a) well J251, 3769.01 m; (b) well J251, $3769.01 \mathrm{~m}$.

4.1. Tectonic Microfractures. Small-scale high-elongation tectonic fractures are formed, and some even cut through rocks and grains. They can connect with other fractures and even form networks to improve seepage $[10,11]$. Tectonic fractures cut through beddings and are straight and even with openings of $0.01-10 \mu \mathrm{m}$ (Figure 2). Most tectonic microfractures are filled with quartz, calcite, and dolomite and rarely with mud (Figure 2). Such tectonic fractures are formed when minerals are destroyed under stress that exceeds their fracture strength $[14,15]$. Their developing planes are straight, even, and open to varying degrees. Tectonic fractures are commonly seen in quartz, feldspar, and other fragile minerals but rarely in clay minerals (Figure 9).

Bedding fractures are related to tectogenesis. Because beddings are the weak surfaces of strata, when the pressure gradient inside a closed system is greater than a critical value, a part of the bedding surface dislocates or opens to form a fracture $[52,56]$. Bedding fractures are nearly parallel to the bedding surface and cross mineral grains. They are typically manifested as one broad head and one gradually sharpening head. Bedding fractures are $0.1-5 \mu \mathrm{m}$ wide and $0.1-10 \mathrm{~mm}$ long; they are mostly filled with mud, iron or quartz, feldspar, calcite, and other minerals in the later stage, with a filling degree of $80 \%$ (Figure 10).

4.2. Diagenetic Microfractures. Diagenetic microfractures result from diagenesis and show no definite orientation. They are open to varying degrees. Diagenetic microfractures exhibit irregular shapes, distributions, and sizes and are mostly branch- or cobweb-like. Common types include diagenetic contraction fractures, organic hydrocarbonproducing fractures, and corroded fractures. Diagenesis contraction fractures are found in kaolinite and other clay minerals, which contract upon dehydration because of their 


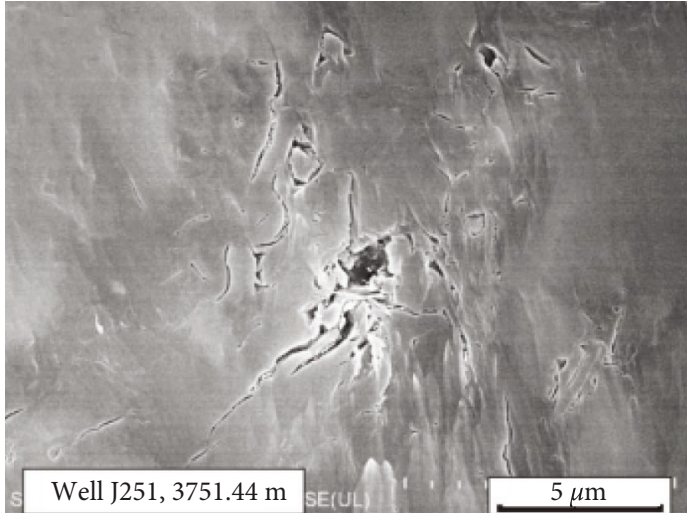

(a)

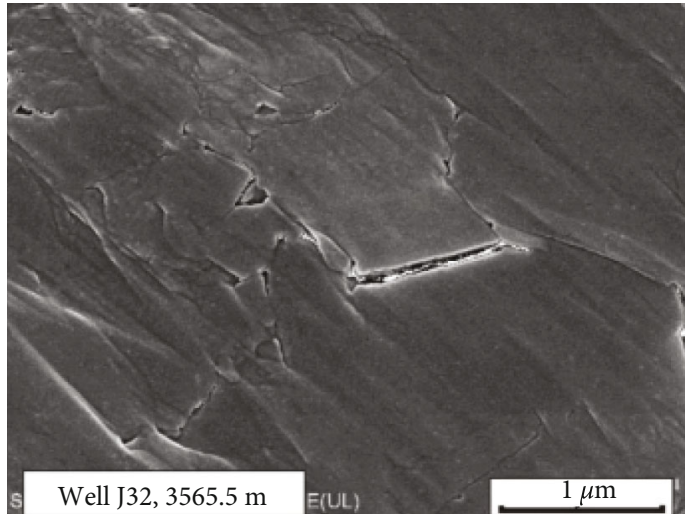

(b)

FIGURE 11: Diagenetic contraction fractures in microscopic scale of the Lucaogou Formation in the Jimsar Sag: (a) well J251, 3751.44 m; (b) well J251, 3565.5 m.

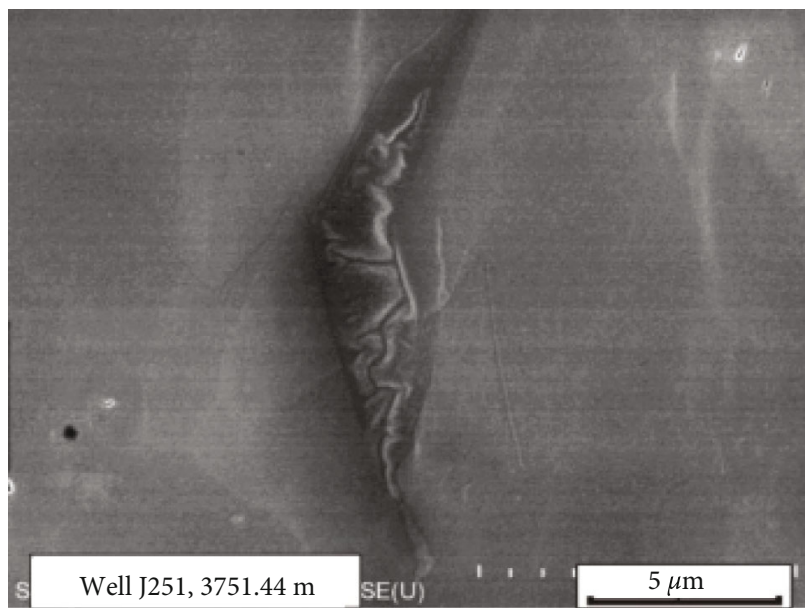

(a)

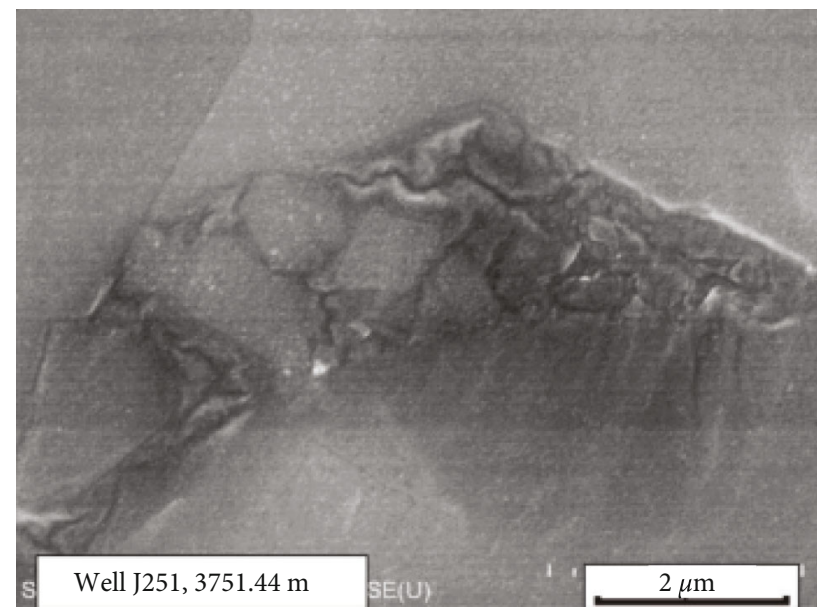

(b)

FiguRE 12: High-pressure microfractures in microscopic scale of the Lucaogou Formation in the Jimsar sag: (a) well J251, 3751.44 m; (b) well J251, 3751.44 m.

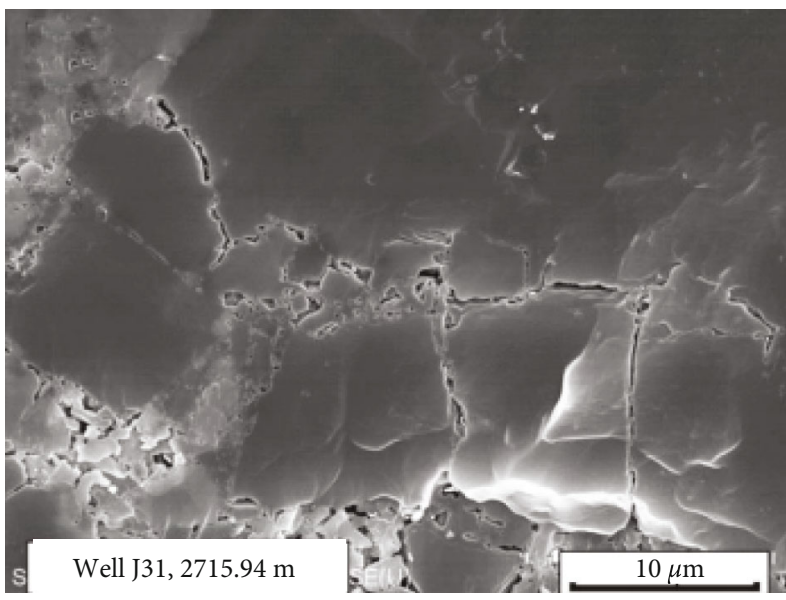

(a)

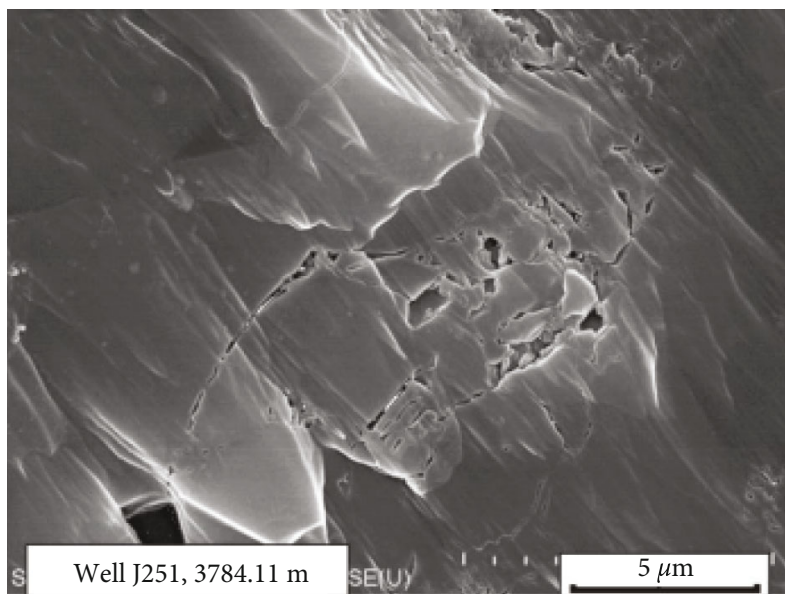

(b)

FIGURE 13: Dissolution fractures in microscopic scale of the Lucaogou Formation in the Jimsar sag: (a) well J31, 2751.94 m; (b) well J251, $3784.11 \mathrm{~m}$. 


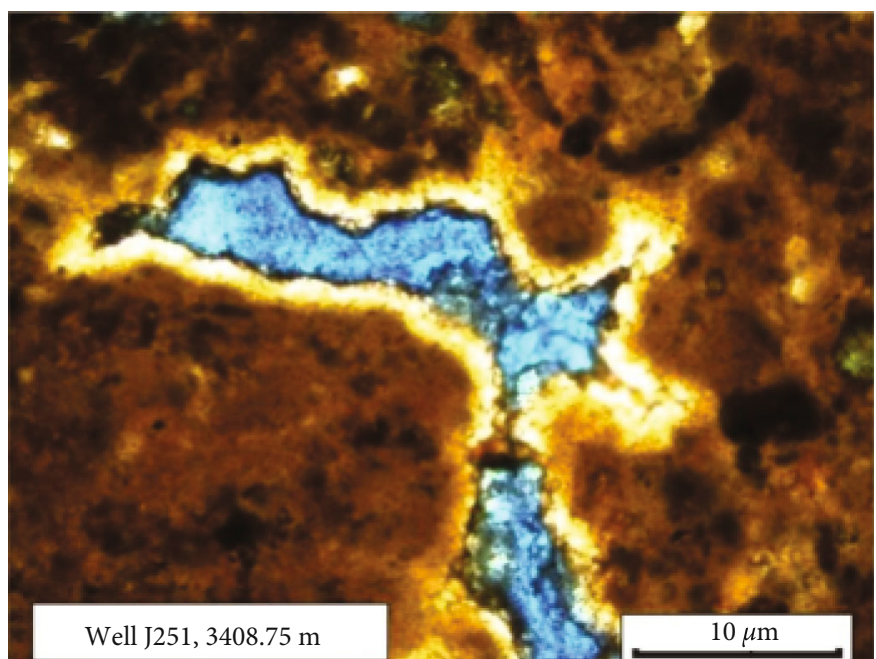

(a)

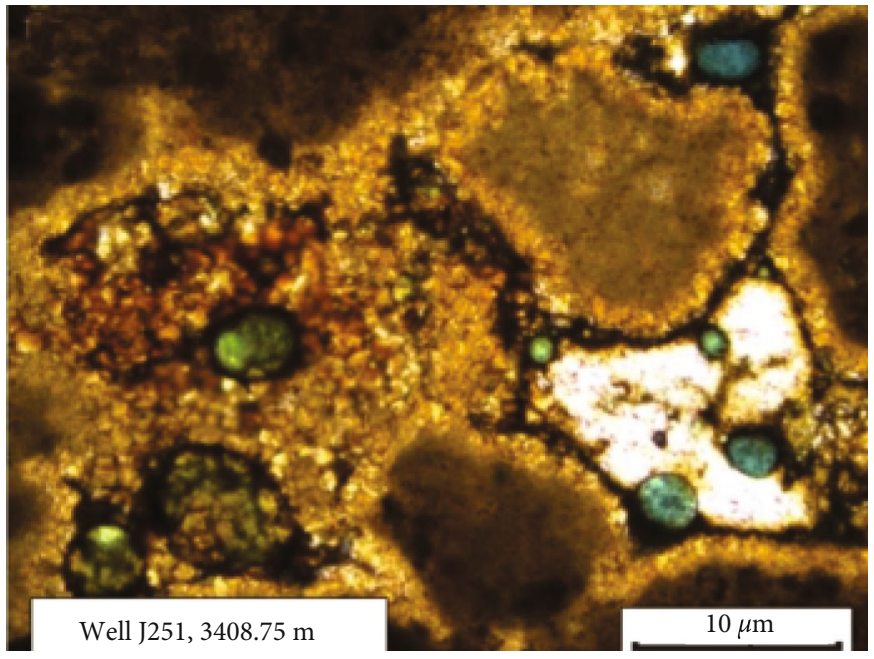

(b)

FIgURE 14: Gravel-edge fractures and corrosion fractures in microscopic scale of the Lucaogou Formation in the Jimsar Sag: (a) well J251, $3408.75 \mathrm{~m}$; (b) well J251, $3408.75 \mathrm{~m}$.

scale-like crystals to form fractures nearly parallel to the mineral layers [57]. High silicon reservoirs form diagenetic contraction fractures because of dehydration, mineral phase transformation, or thermodynamic contraction. Diagenetic contraction fractures are commonly seen in stratified minerals and exhibit diverse shapes, including straight or curved. They do not extend considerably but are well connected with large openings (Figure 11).

Organic hydrocarbon-producing high-pressure fractures are intragranular porous fractures that form when organicrich argillaceous interlayers in tight reservoirs are sufficiently mature and buried sufficiently deep (Figure 12). This is probably because porous fractures are formed because of organic depletion after hydrocarbon generation from kerogen, water consumption owing to hydrocarbon generation, or increased pressure owing to hydrocarbon formation. Moreover, organic matter and adjacent minerals can form porous fractures owing to hydrocarbon formation, likely attributed to

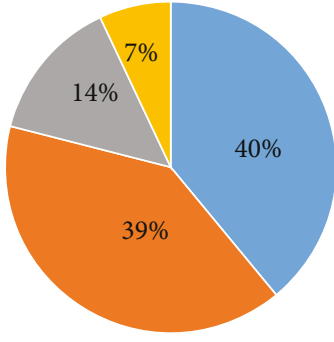

$$
\begin{aligned}
& \text { Tectonic microfracture } \\
& \text { Diagenetic microfracture } \\
& \text { Granular microfracture } \\
& \text { Others }
\end{aligned}
$$

FIGURE 15: Classification diagram of genetic types of microfractures. 


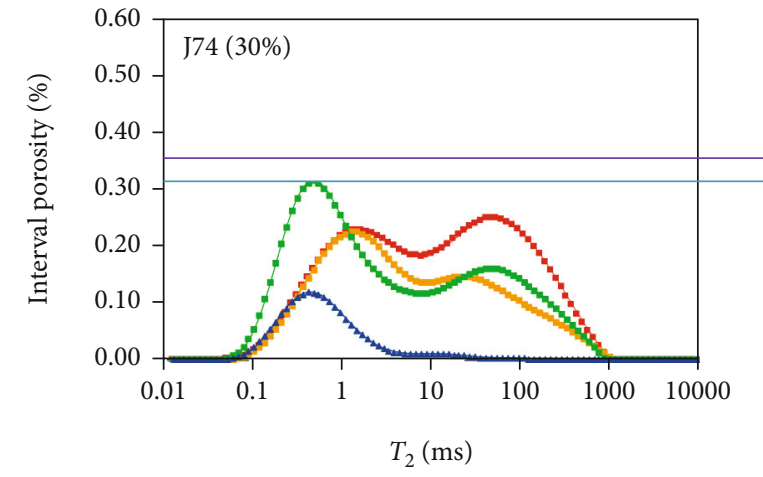

(a)

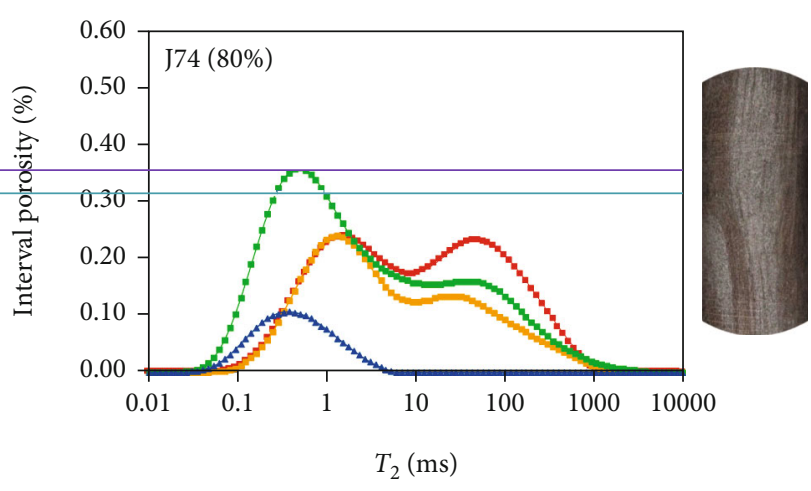

(b)

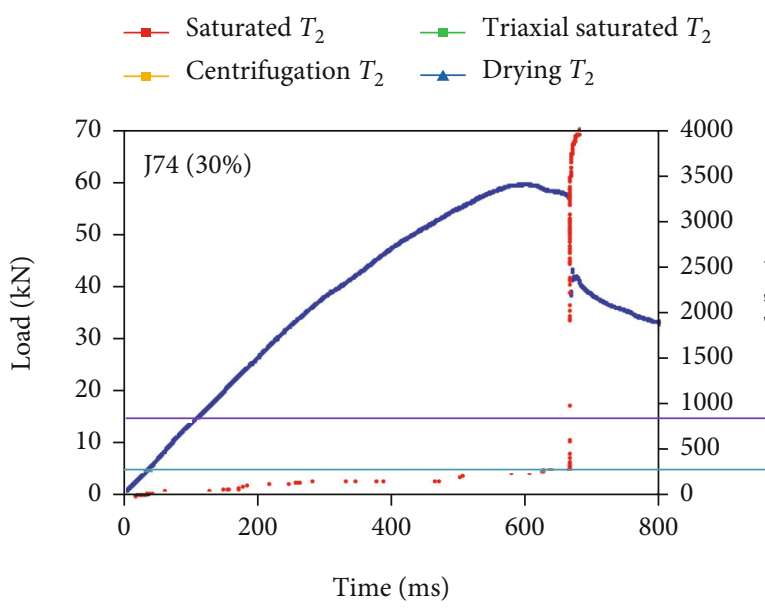

(c)

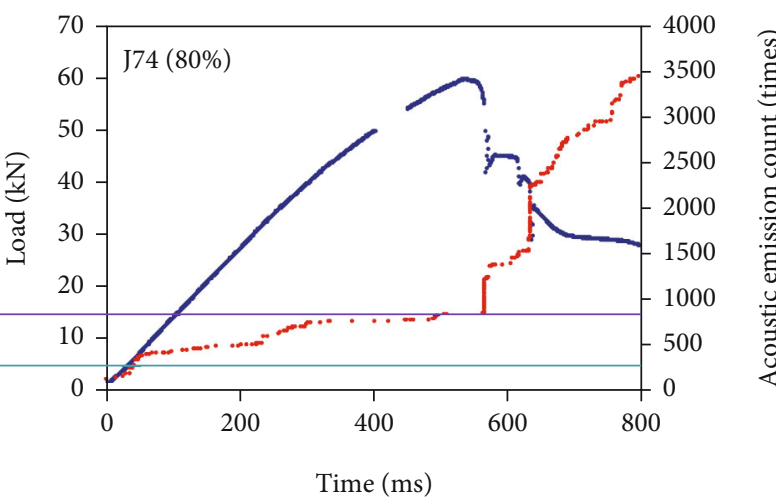

(d)

FIGURE 16: Comparison between the NMR experiment and the acoustic emission experiment of well J174 based on a variable saturation: (a) NMR experiment of well J74 with 30\% water saturation; (b) NMR experiment of well J74 with 80\% water saturation; (c) AE experiment of well J74 with $30 \%$ water saturation; (d) AE experiment of well J74 with $80 \%$ water saturation.

organic matter contraction or pressure increment after hydrocarbon production.

Corroded fractures are formed when organic acids or underground fluids generated from hydrocarbon formation corrode the rock $[14,16,17,58-60]$. The organic acids formed from the thermal evolution of organic matter provide $\mathrm{H}^{+}$and metallic elements for complexation, improving the solubility of minerals and affecting their stability. This leads to intragranular or intergranular corrosion. The degree of corrosion is related to the mineral type because different minerals exhibit differing levels of corrosion resistance. Calcite, dolomite, and other carbonates are the most easily corroded, followed by quartz and feldspar. Clay minerals show the highest corrosion resistance (Figure 13).

4.3. Granular Microfractures. Granular microfractures are formed along some fractured grains or particulate joints because of external forces and are mainly related to corrosion [61]. Granular microfractures mainly include intragranular and marginal fractures. Early-stage fractures are filled in the later stages and are less significant; however, once the filling corrodes, the fractures become more connected and significant [62-64]. SEM analysis revealed the intergranular fractures that formed more easily among different minerals but not within the same mineral type (Figure 14). Owing to different crystal lattices among different minerals, they grow in different directions and thus can easily form intergranular fractures. Within the same mineral type, the formation of intergranular fractures is rare owing to consistent crystal lattice directions. Moreover, the mechanical properties differ among minerals; hence, they deform differently when subjected to the same stress, which also encourages intergranular fractures.

Generally, the Lucaogou Formation mainly developed diagenetic microfractures followed by tectonic microfractures, with little formation of granular microfractures (Figure 15). Statistical analysis of the cast sections showed that tectonic microfractures (directional microfractures) mostly developed near well J174. This indicates that besides the large-scale basin-wide geological activities, small-scale geological activities very likely occurred at this well. Diagenetic microfractures were mainly near well J34, indicating that this site is rich in organic matter and fragile minerals.

\section{Results and Discussion}

5.1. Relationship between Microfractures and Pore Fluid. The relationship between fractures and the pore fluid was 
TABLE 2: Effect of fluids on mechanical properties of the Lucaogou Formation tight sandstones in the Jimsar Sag, Junggar Basin.

\begin{tabular}{|c|c|c|c|c|c|c|c|}
\hline $\begin{array}{l}\text { Water saturation } \\
(\%)\end{array}$ & $\begin{array}{c}\text { Compressive strength } \\
(\mathrm{GPa})\end{array}$ & $\begin{array}{c}\text { Ratio of decrease } \\
(\%)\end{array}$ & $\begin{array}{c}\text { Elastic modulus } \\
(\mathrm{GPa})\end{array}$ & $\begin{array}{c}\text { Ratio of decrease } \\
(\%)\end{array}$ & $\begin{array}{l}\text { Poisson's } \\
\text { ratio }\end{array}$ & $\begin{array}{c}\text { Ratio of increase } \\
(\%)\end{array}$ & Group \\
\hline 0 & 156.94 & & 29.75 & & 0.259 & & G1 \\
\hline 30 & 151.44 & 0.035 & 22.78 & 0.23 & 0.258 & 0.0039 & G1 \\
\hline 80 & 146.12 & 0.035 & 20.23 & 0.11 & 0.295 & 0.1434 & G1 \\
\hline 100 & 80.58 & 0.449 & 7.52 & 0.63 & 0.554 & 0.8780 & G1 \\
\hline 0 & 156.33 & & 25.01 & & 0.283 & & G2 \\
\hline 30 & 146.16 & 0.065 & 21.65 & 0.13 & 0.284 & 0.0035 & G2 \\
\hline 90 & 90.22 & 0.321 & 14.30 & 0.34 & 0.289 & 0.0176 & G2 \\
\hline 100 & 80.23 & 0.191 & 8.30 & 0.42 & 0.446 & 0.5433 & G2 \\
\hline 0 & 146.21 & & 26.35 & & 0.214 & & G3 \\
\hline 30 & 140.90 & 0.036 & 20.99 & 0.20 & 0.221 & 0.0327 & G3 \\
\hline 70 & 93.73 & 0.335 & 18.88 & 0.10 & 0.368 & 0.6652 & G3 \\
\hline 100 & 79.26 & 0.154 & 15.36 & 0.19 & 0.392 & 0.0652 & G3 \\
\hline
\end{tabular}

TABLE 3: Test data of core sample from well J34.

\begin{tabular}{|c|c|c|c|c|c|c|c|c|c|}
\hline \multirow{2}{*}{ Sample } & \multicolumn{4}{|c|}{ Nonbrittle mineral content (\%) } & \multicolumn{5}{|c|}{ Brittle mineral content (\%) } \\
\hline & Clay mineral & Chlorite & Illite & Mixed-layer illite & Quartz & Calcite & Dolomite & Feldspar & Pyrite \\
\hline $\mathrm{J} 37-1$ & 44 & 24 & 59 & 16 & 43 & 1 & 2 & 6 & 4 \\
\hline $\mathrm{J} 37-2$ & 24 & 10 & 71 & 19 & 63 & 4 & 6 & 1 & 2 \\
\hline $\mathrm{J} 37-3$ & 28 & 11 & 70 & 19 & 48 & 7 & 4 & 12 & 1 \\
\hline $\mathrm{J} 37-4$ & 25 & 14 & 55 & 31 & 43 & 8 & 8 & 13 & 3 \\
\hline
\end{tabular}

evaluated in terms of lithomechanical properties. The NMR $T_{2}$ spectrum of well J174 revealed additional microfractures and micropores as the water saturation increased. The same results were obtained from the $\mathrm{AE}$ experiments. In Figure 16, the curve of the AE count under the purple line indicates the number of microfractures, and that above the purple line indicates fractures. The AE ring count significantly increased as the water saturation increased, indicating the formation of additional microfractures.

The results of the triaxial experiments showed that the deformation parameters of rocks followed different trends depending on the degree of saturation. As the water content increased, the compressive strength and elastic modulus decreased by $45 \%-65 \%$ compared with the dry condition. Moreover, Poisson's ratio increased by $80 \%$ compared with the dry condition. These results indicate that the presence of a pore fluid affects the mechanical properties of rocks (Table 2).

As the pore fluid content increased, the compressive strength and elastic modulus decreased more rapidly, Poisson's ratio increased faster, and pore fluids more severely affected the mechanical properties of rocks. Contrarily, as the pore fluid content decreased, the compressive strength and elastic modulus decreased more slowly, Poisson's ratio increased more slowly, and pore fluids less severely affected the mechanical properties of rocks. The AE experiments showed that the AE ring count was proportional to the number of microfractures and significantly increased with increasing pore fluid content, indicating the formation of additional microfractures. Furthermore, the number of microfractures showed a positive correlation with the pore fluid content.

The pore fluid content affected not only the deformation parameters but also the deformation and failure mechanisms of the rocks. The presence of pore fluid changed the rock strength and deformation because it can relieve the intergranular cohesive strength of rocks and accelerate the molecular motion of fluids. The liquid and gas filling the microfractures generate pore pressure, which partially offsets the total stress imposed on a random section on rocks, including peripheral pressure and tectonic stress. Such pressure decreases the elastic yield strength of rocks and makes them more susceptible to deformation, further affecting the formation and development of internal microfractures in the rocks. The presence of pore fluid also decreases the shear strength of rocks and makes them more susceptible to shear deformation. In summary, the pore fluid content mainly affects the mechanical properties of rocks and controls the developing degree of tectonic fractures. However, changes in the lithomechanical properties have little effect on the development of bedding fractures.

5.2. Relationship between Microfractures and Mineral Composition. Ten rock samples were selected and found to be rich in carbonate and fragile minerals (Table 3). After the samples were sealed, triaxial experiments were conducted. The rocks were compressed and saturated with water at certain degrees of mineralisation. The rock samples were 
TABLE 4: NMR test results of samples from well J34.

\begin{tabular}{lcccr}
\hline Sample & Length $(\mathrm{cm})$ & Diameter $(\mathrm{cm})$ & Fracture/microfracture content (\%) & $\begin{array}{c}\text { Nuclear magnetic analysis } \\
\text { Water saturation (\%) } \\
\text { Saturated }\end{array}$ \\
\hline J37-1 & & 2.539 & 17.33 & 100 \\
$\mathrm{~J} 37-2$ & 5.082 & 2.539 & 3.71 & 100 \\
$\mathrm{~J} 37-3$ & 5.051 & 2.531 & 9.61 & 84.15 \\
$\mathrm{~J} 37-4$ & 5.086 & 2.539 & 12.72 & 86.58 \\
\hline
\end{tabular}

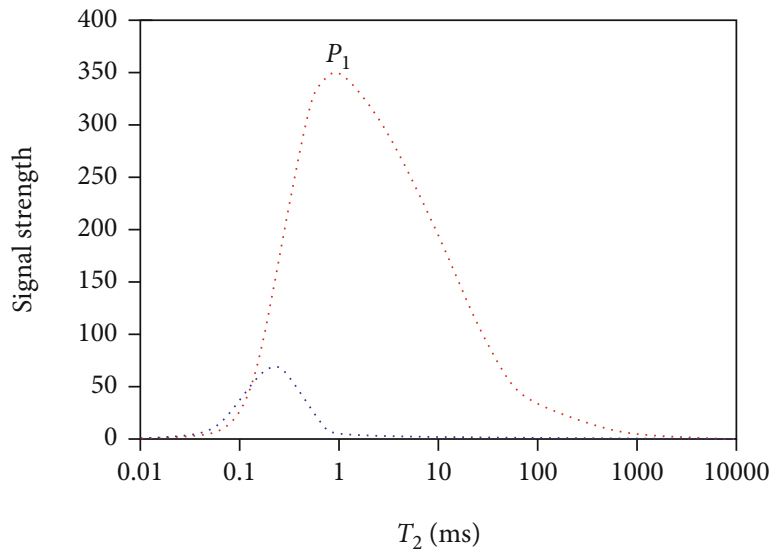

Centrifugation $T_{2}$ Saturated $T_{2}$

(a)

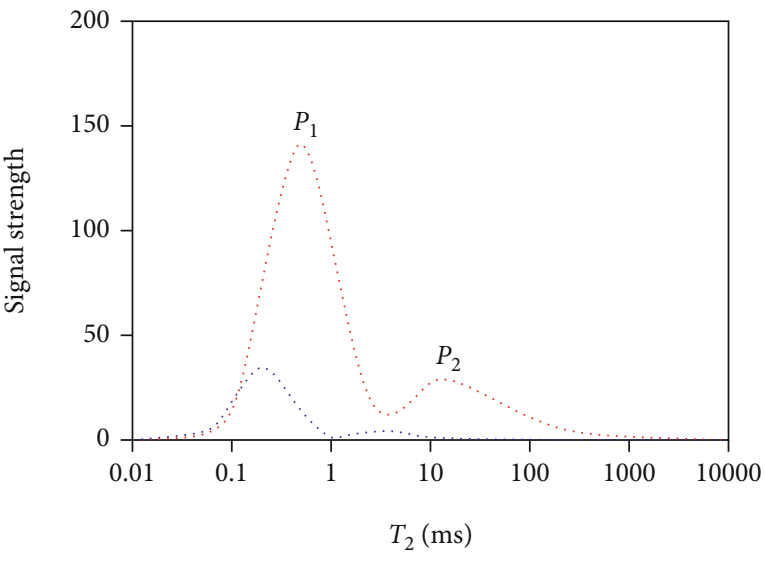

Centrifugation $T_{2}$ Saturated $T_{2}$ (b)

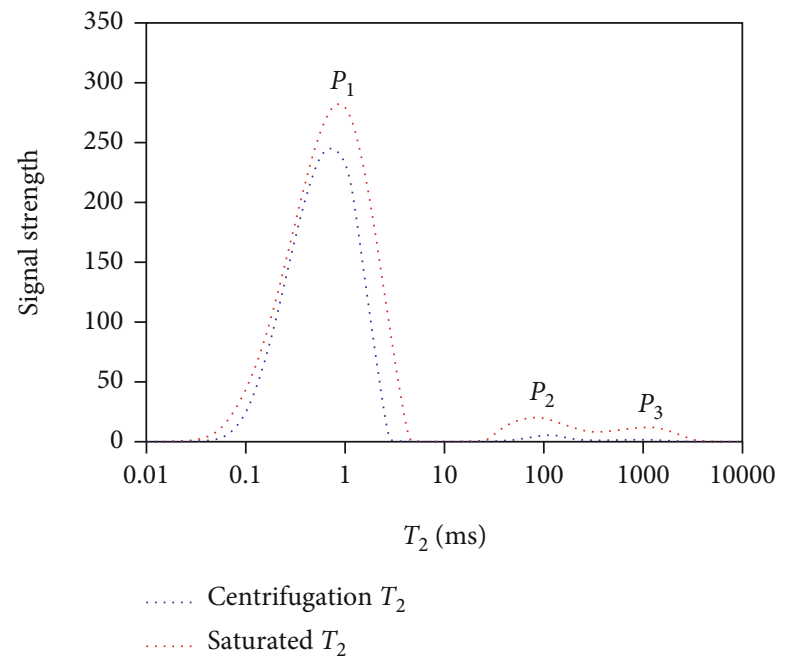

(c)

FIgURE 17: $T_{2}$ features of samples: (a) NMR of type I fractures; (b) NMR of type II fractures; (c) NMR of type III fractures.

displaced with oil and salts. According to laboratory standards, NMR was then applied to the saturated water cores. The NMR $T_{2}$ spectra were used to select rocks according to their microfracture characteristics (Figure 5) and calculate the corresponding fracture/microfracture ratio (Table 4).

The Lucaogou Formation mainly consists of five facies: sand detritus dolomite, micrite dolomite, dolomitic fine siltstone, argillaceous fine siltstone, and mudstone. The first member of Lucaogou (Lu1) mainly shows three types of sedimentation: graded in situ mixed sedimentation, combined marginal mixed sedimentation, and graded parent-derived mixed sedimentation. The second member of Lucaogou (Lu2) mainly exhibits three types of sedimentation: mutant in situ mixed sedimentation, graded in situ mixed sedimentation, and combined marginal mixed sedimentation. The mechanical properties of the reservoir rocks were mainly 


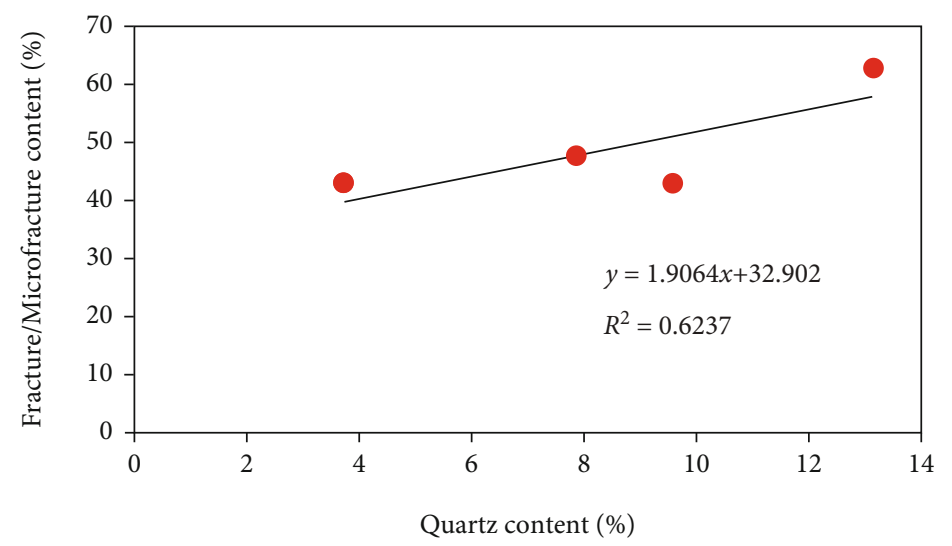

(a)

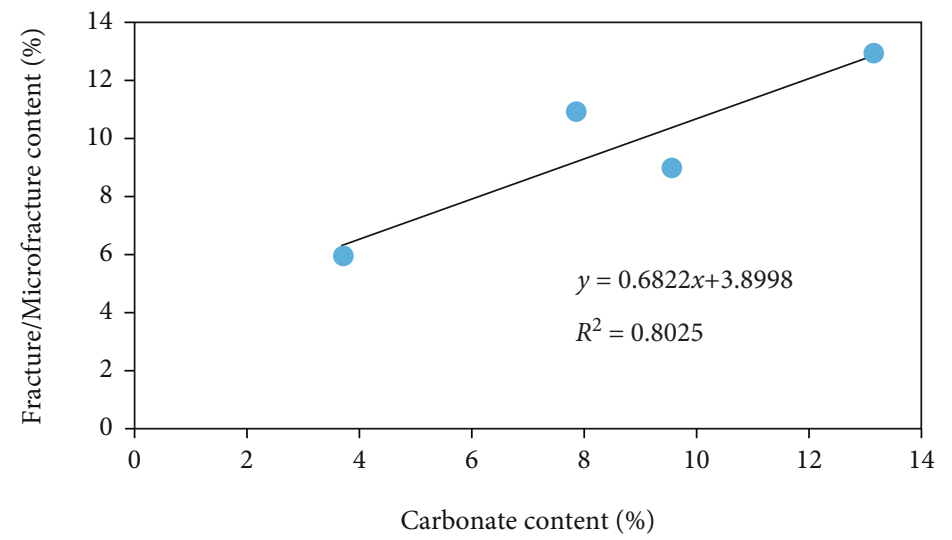

(b)

FIGURE 18: $T_{2}$ features of samples: (a) relationship between quartz content and microfractures; (b) relationship between carbonate content and microfractures.

affected by two components: (1) brittle components, such as calcareous and siliceous components, and (2) plastic components, such as argillaceous components [65].

The NMR images after triaxial compression experiments showed that the compressed fractures were mainly distributed as three types. Type I showed only one peak $\left(P_{1}\right)$, and the fractures were distributed in areas with a short relaxation time $\left(T_{2}<10 \mathrm{~ms}\right)$, indicating that only tiny pores were formed (Figure 17(a)). Type II exhibited two peaks $\left(P_{1}\right.$ and $\left.P_{2}\right)$ distributed in areas with relatively long and short relaxation times, respectively, suggesting the development of tiny pores and microfractures (Figure 17(b)). Type III exhibited three peaks $\left(P_{1}-P_{3}\right)$ with long relaxation times, suggesting the formation of macrofractures (Figure 17(c)). This type of fracture is difficult to observe using NMR. The presence of macrofractures increased the breakability of the rocks in the centrifugation experiments.

In tight sandstone, a higher quartz content was positively correlated with a larger fracture/microfracture ratio (Figure 18(a)). Moreover, a higher carbonate content was positively correlated with a larger fracture/microfracture ratio (Figure 18(b)). Quartz is mainly composed of $\mathrm{SiO}_{2}$. According to the rock rupture mechanism, when quartz grains are stressed, their margins easily form marginal frac- tures, which increase the pore permeability. Rocks containing a high silicon content are more brittle and can more easily form fractures. Furthermore, carbonate minerals are more prone to corrosion, forming corroded microfractures. Rocks with more carbonates can form microfractures more easily.

5.3. Relationship between Microfractures and Lithology. Sections from 10 wells in the study area were sent for granularity analysis. Combined with the lithological data, the sandstone in the study area was found to be generally fine-grained and well separated. Fine-sand and mediumsand rocks accounted for $60 \%$ and $23 \%$, respectively. Microfractures also developed in dolomite, dolomitic mudstone, mudstone, and dolomitic fine siltstone. The types and characteristics of microfractures differed depending on lithology. Mudstone was mainly black or grey black and contained few macrofractures. It mainly developed with organic hydrocarbon-producing high-pressure fractures and corroded fractures. The dolomitic mudstone was greyish white and mainly developed with bedding fractures. The dolomitic siltstone was greyish white and mainly developed with bedding fractures and tectonic fractures.

The casting thin sections and 200 SEM images from nearly 20 wells in the Lucaogou Formation were classified 


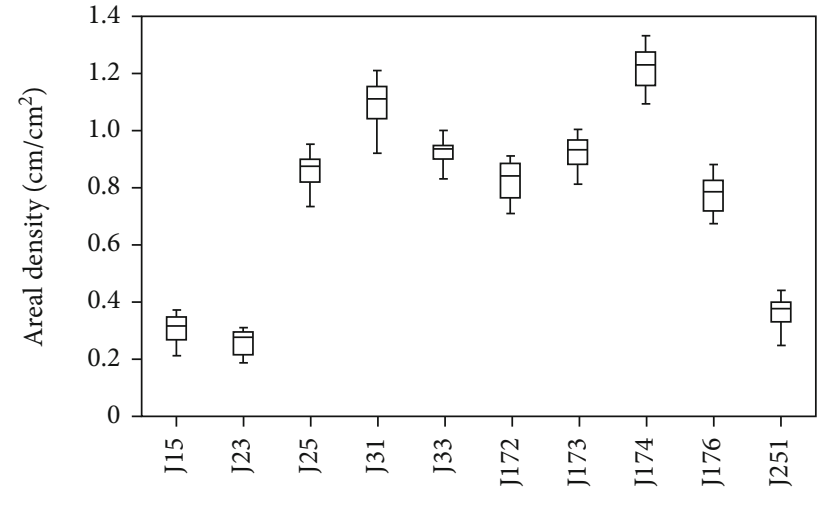

Well name

(a)

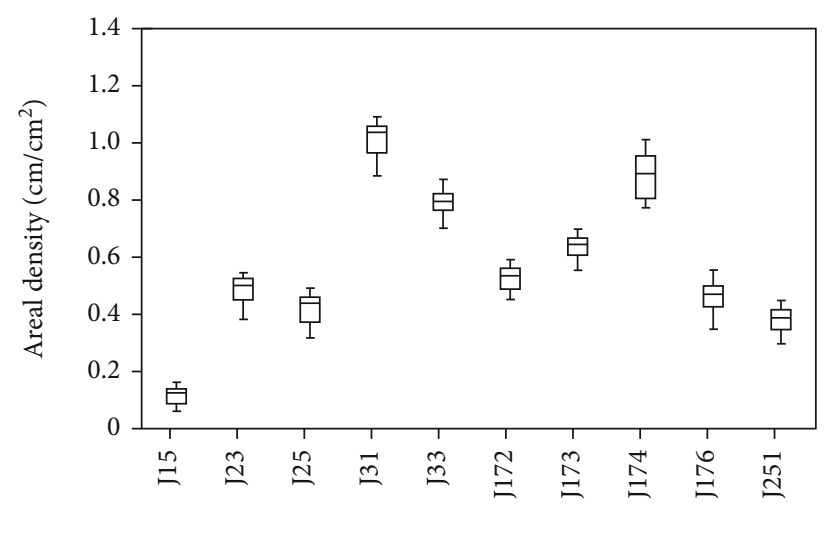

Well name

(c)

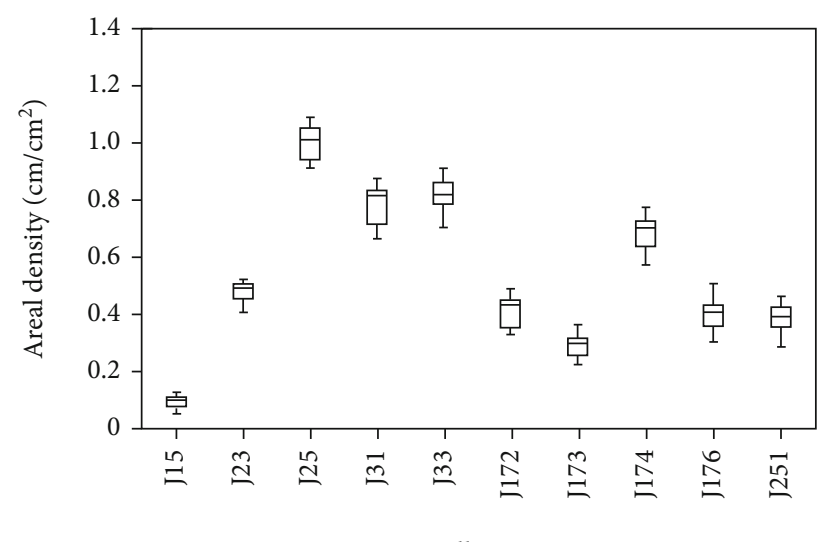

Well name

(e)

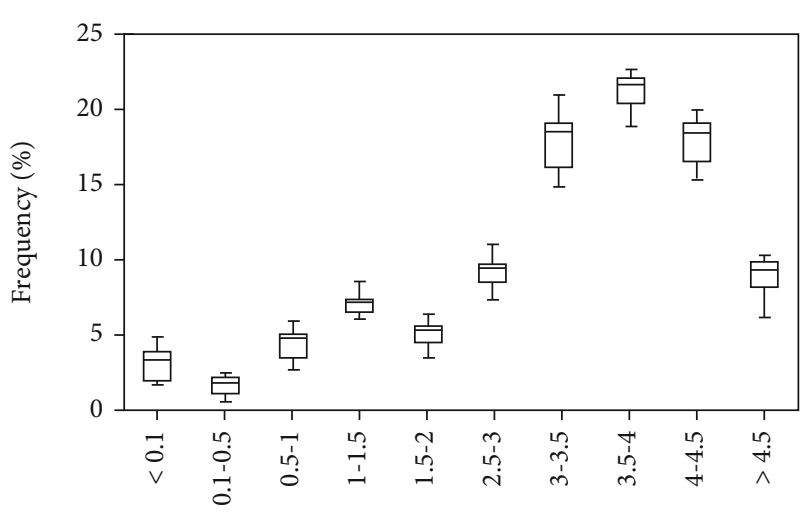

Opening $(\mu \mathrm{m})$

(b)

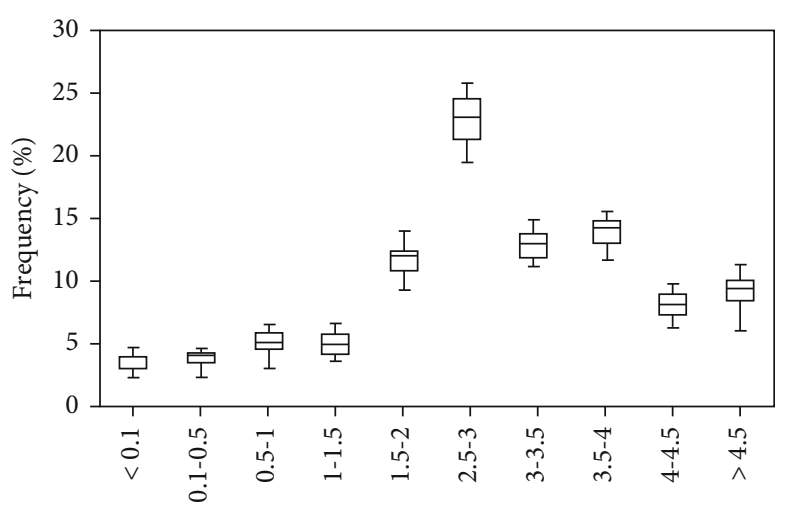

Opening $(\mu \mathrm{m})$

(d)

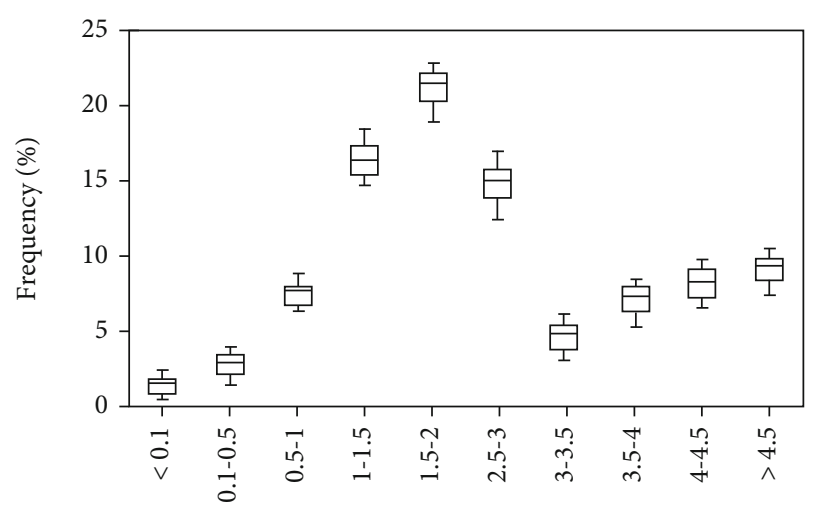

Opening $(\mu \mathrm{m})$

(f)

Figure 19: Continued. 


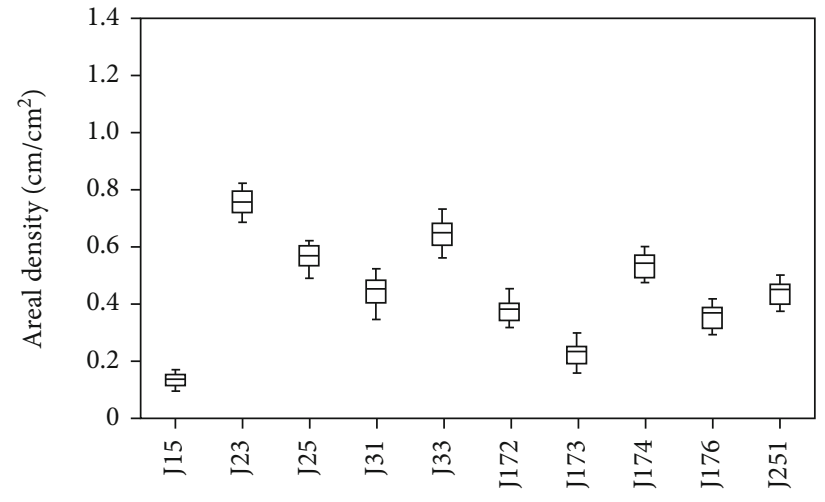

Well name

(g)

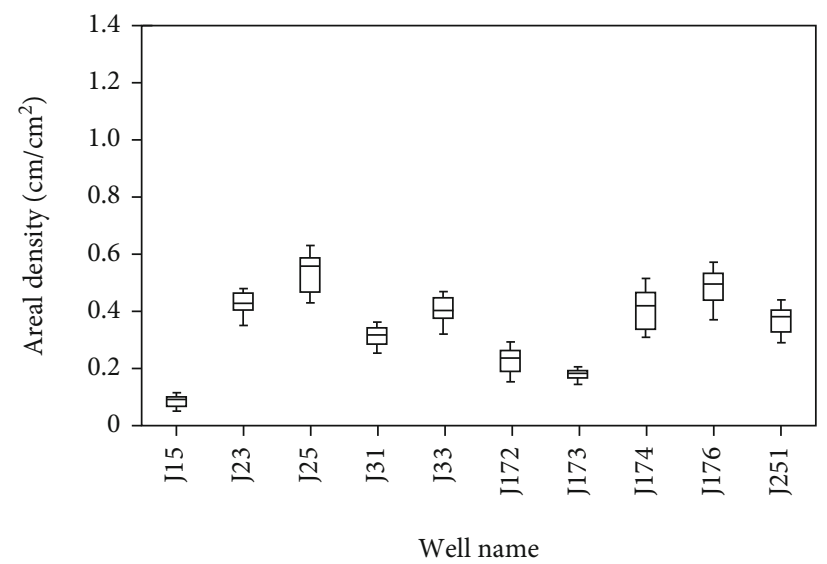

(i)

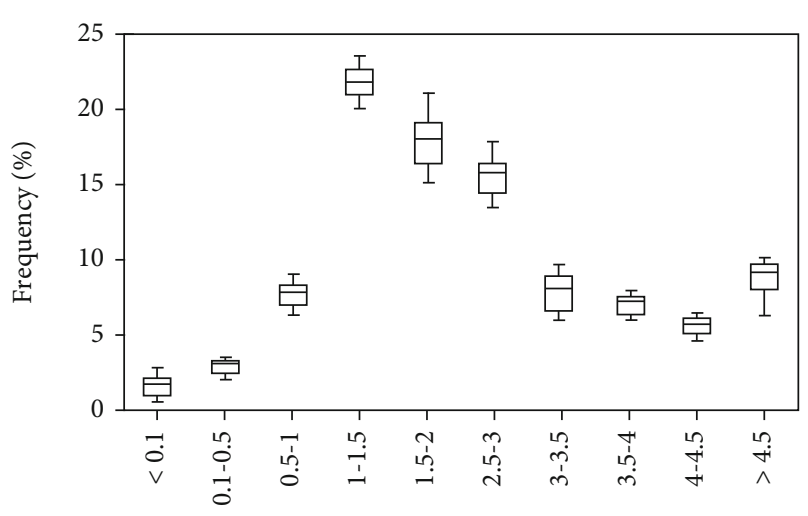

Opening $(\mu \mathrm{m})$

(h)

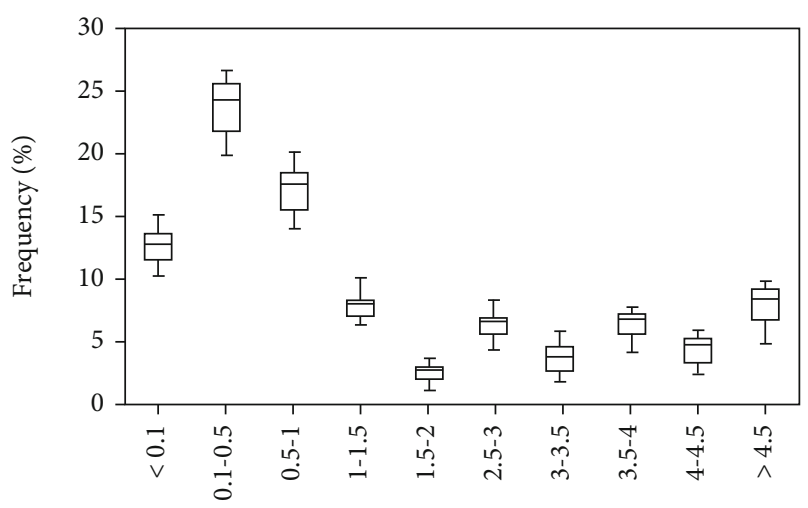

Opening $(\mu \mathrm{m})$

(j)

Figure 19: The correlation diagram of microfractures and lithology: (a) microfracture surface density of sandy dolomite; (b) microfracture frequency of sandy dolomite; (c) microfracture surface density of micritic dolomite; (d) microfracture frequency of micritic dolomite; (e) microfracture surface density of dolomitic fine sandstone; (f) microfracture frequency of dolomitic fine sandstone; (g) microfracture surface density of argillaceous siltstone; (h) microfracture frequency of argillaceous siltstone; (i) microfracture surface density of mudstone; (j) microfracture frequency of mudstone.

according to lithology, and the microfractures were statistically analysed (Figure 19). The microfractures clearly developed according to the lithology. Generally, dolomite showed the highest microfracture density, followed by dolomitic siltstone, dolomitic mudstone, and mudstone. Hence, the microfracture development was observed to be closely related to lithology.

5.4. Relationship between the Fracture Space and Stratum Thickness. The Lucaogou Formation is enriched with hydrocarbon source rocks and has two major sweet points. The upper sweet point is divided into four sublayers: STD-1, STD-2, STD-3, and STD-4. The lower sweet point is segregated into six sublayers: XTD-1, XTD-2, XTD-3, XTD-4, XTD-5, and XTD-6. Statistical results showed that when the rock mechanical parameters and stress conditions were the same, thin rock layers were more likely to form highdensity microfractures than thick rock layers. Because dolomite is rich in carbonate minerals, the microfractures formed from its corrosion affected the results. Hence, the microfrac- tures in sections collected from sandstone layers of the study area were statistically analysed. The sections from the upper and lower sweet points of the Lucaogou Formation were statistically analysed under microscopy. Up to a stratum thickness of $2.5 \mathrm{~m}$, the average single-well fracture space increased with the stratum thickness and the fracture density decreased. When the stratum thickness was greater than $2.5 \mathrm{~m}$, the fracture space remained constant. Lithomechanical experiments verified that when the same stress ratio was applied for a certain time, the fracture space increased with the stratum thickness.

\section{Conclusions}

(1) The Lucaogou Formation mainly developed diagenetic microfractures followed by tectonic microfractures, with little development of granular microfractures. The developing degree of the microfractures showed correlations with the pore 
fluid content, mineral composition, lithology, and stratum thickness

(2) The count of AE events showed a positive correlation with the microfracture density. A higher pore fluid content indicated a lower compressive strength of the rocks and a higher likelihood of microfracture formation

(3) NMR obtained the fracture/microfracture percentage ratio. A higher fracture/microfracture percentage ratio indicated a higher content of fragile minerals in the rock and thus a higher likelihood of microfracture development

(4) Thin rock layers were more likely to form highdensity microfractures than thick rock layers when the rock mechanical parameters and stress conditions were the same

\section{Data Availability}

The main data used to support the study is available within the article. Readers interested in the data can communicate with the corresponding authors and obtain this data by email.

\section{Conflicts of Interest}

The authors declare that they have no conflicts of interest.

\section{Authors' Contributions}

Xiangye Kong and Haowei Yuan contributed equally to this work.

\section{Acknowledgments}

This work is financially supported by grants from the National Natural Science Foundation of China (No. 42002050) and the China Postdoctoral Science Foundation Funded Project (No. 2020M680815).

\section{References}

[1] B. M. Newberry, R. F. Nelson, and U. Ahmed, "Prediction of vertical hydraulic fracture migration using compressional and shear wave slowness," in SPE/DOE Low Permeability Gas Reservoirs Symposium, Society of Petroleum Engineers, 1985.

[2] S. E. Laubach, "Subsurface fractures and their relationship to stress history in East Texas Basin sandstone," Tectonophysics, vol. 156, no. 1-2, pp. 37-49, 1988.

[3] J. C. Lorenz, N. R. Warpinski, P. T. Branagan, and A. R. Settler, "Fracture characteristics and reservoir behavior of stresssensitive fracture systems in flat-lying lenticular formations," Journal of Petroleum Technology, vol. 41, no. 6, pp. 615-622, 1989.

[4] J. F. Gale, S. E. Laubach, J. E. Olson, P. Eichhubl, and A. Fall, "Natural fractures in shale: a review and new observations," AAPG bulletin, vol. 98, no. 11, pp. 2165-2216, 2014.

[5] R. Wang, Z. Hu, C. Sun et al., "Comparative analysis of shale reservoir characteristics in the Wufeng-Longmaxi (O3w-S1l) and Niutitang $(€ 1 n)$ Formations: a case study of wells JY1 and TX1 in the southeastern Sichuan Basin and its neighboring areas, southwestern China," Interpretation, vol. 6, no. 4, pp. 31-35, 2018.

[6] D. D. Liu, C. Zhang, Q. Luo et al., "Development characteristics and controlling factors of natural fractures in Permian Lucaogou Formation tight reservoir in Jimsar Sag, Junggar Basin," China Petroleum Exploration, vol. 22, no. 4, p. 36, 2017.

[7] R. G. Miller and S. R. Sorrell, The Future of Oil Supply, vol. 372, no. 2006, 2014The Royal Society Publishing, 2014.

[8] Z. Xu, P. Zhao, Z. Wang, M. Ostadhassan, and Z. Pan, "Characterization and consecutive prediction of pore structures in tight oil reservoirs," Energies, vol. 11, no. 10, p. 2705, 2018.

[9] B. Yuan and D. A. Wood, "A holistic review of geosystem damage during unconventional oil, gas and geothermal energy recovery," Fuel, vol. 227, pp. 99-110, 2018.

[10] H. Zhang, R. Zhang, Y. Haijun et al., "Characterization and evaluation of ultra-deep fracture-pore tight sandstone reservoirs: a case study of Cretaceous Bashijiqike Formation in Kelasu tectonic zone in Kuqa foreland basin, Tarim, NW China," Petroleum Exploration and Development, vol. 41, no. 2, pp. 175-184, 2014.

[11] W. Xiaoqi, S. Liang, Z. Rukai et al., "Application of charging effects in evaluating storage space of tight reservoirs: a case study from Permian Lucaogou Formation in Jimusar Sag, Junggar Basin, NW China," Petroleum Exploration and Development, vol. 42, no. 4, pp. 516-524, 2015.

[12] W. Huang, S. Lu, O. S. Hersi, M. Wang, S. Deng, and R. Lu, "Reservoir spaces in tight sandstones: classification, fractal characters, and heterogeneity," Journal of Natural Gas Science and Engineering, vol. 46, pp. 80-92, 2017.

[13] B. Liu, Y. Yang, J. Li, Y. Chi, J. Li, and X. Fu, "Stress sensitivity of tight reservoirs and its effect on oil saturation: a case study of Lower Cretaceous tight clastic reservoirs in the Hailar Basin, Northeast China," Journal of Petroleum Science and Engineering, vol. 184, article 106484, 2020.

[14] J. E. Olson, S. E. Laubach, and R. H. Lander, "Combining diagenesis and mechanics to quantify fracture aperture distributions and fracture pattern permeability," Geological Society, London, Special Publications, vol. 270, no. 1, pp. 101-116, 2007.

[15] J. E. Olson, S. E. Laubach, and R. H. Lander, "Natural fracture characterization in tight gas sandstones: Integrating mechanics and diagenesis," AAPG bulletin, vol. 93, no. 11, pp. 1535-1549, 2009.

[16] J. Gallagher Jr., M. Friedman, J. Handin, and G. Sowers, "Experimental studies relating to microfracture in sandstone," Tectonophysics, vol. 21, no. 3, pp. 203-247, 1974.

[17] J.-F. Barthélémy, "Effective permeability of media with a dense network of long and micro fractures," Transport in porous media, vol. 76, no. 1, pp. 153-178, 2009.

[18] D. Tiab and E. C. Donaldson, Petrophysics: Theory and Practice of Measuring Reservoir Rock and Fluid Transport Properties, Gulf professional publishing, 2015.

[19] P. A. Geiser and S. Sansone, "Joints, microfractures, and the formation of solution cleavage in limestone," Geology, vol. 9, no. 6, pp. 280-285, 1981.

[20] S. Yin, D. Lv, and W. Ding, "New method for assessing microfracture stress sensitivity in tight sandstone reservoirs based on acoustic experiments," International Journal of Geomechanics, vol. 18, no. 4, article 04018008, 2018. 
[21] W. Wawersik and C. Fairhurst, "A study of brittle rock fracture in laboratory compression experiments," International Journal of Rock Mechanics and Mining Sciences \& Geomechanics Abstracts, vol. 7, pp. 561-575, 1970.

[22] L. Germanovich, R. Salganik, A. Dyskin, and K. Lee, "Mechanisms of brittle fracture of rock with pre-existing cracks in compression," Pure and Applied Geophysics, vol. 143, no. 1, pp. 117-149, 1994.

[23] C. Tang, H. Liu, P. Lee, Y. Tsui, and L. Tham, "Numerical studies of the influence of microstructure on rock failure in uniaxial compression - part I: effect of heterogeneity," International Journal of Rock Mechanics and Mining Sciences, vol. 37, no. 4, pp. 555-569, 2000.

[24] K. Bjørlykke, "Lithological control on fluid flow in sedimentary basins," in Fluid Flow and Transport in Rocks, pp. 1534, Springer, 1997.

[25] J. Wang and S. S. Rahman, "An investigation of fluid leak-off due to osmotic and capillary effects and its impact on microfracture generation during hydraulic fracturing stimulation of gas shale," EUROPEC, 2015.

[26] C. Li, D. Liu, Y. Cai, and Y. Yao, "Fracture permeability evaluation of a coal reservoir using geophysical logging: a case study in the Zhengzhuang area, southern Qinshui Basin," Energy Exploration \& Exploitation, vol. 34, no. 3, pp. 378-399, 2016.

[27] K. W. Shanley, R. M. Cluff, and J. W. Robinson, "Factors controlling prolific gas production from low-permeability sandstone reservoirs: implications for resource assessment, prospect development, and risk analysis," AAPG bulletin, vol. 88, no. 8, pp. 1083-1121, 2004.

[28] D. Jinhu, L. He, M. Desheng, F. Jinhua, W. Yuhua, and Z. Tiyao, "Discussion on effective development techniques for continental tight oil in China," Petroleum Exploration and Development, vol. 41, no. 2, pp. 217-224, 2014.

[29] J. Lai, G. Wang, Y. Ran, Z. Zhou, and Y. Cui, "Impact of diagenesis on the reservoir quality of tight oil sandstones: the case of Upper Triassic Yanchang Formation Chang 7 oil layers in Ordos Basin, China," Journal of Petroleum Science and Engineering, vol. 145, pp. 54-65, 2016.

[30] L. C. Kuang, Y. Tang, and D. W. Lei, "Formation conditions and exploration potential of tight oil in the Permian saline lacustrine dolomitic rock, Junggar Basin, NW China," Petroleum Exploration and Development, vol. 39, no. 6, pp. 700$711,2012$.

[31] C. Zhang, D. Zhu, Q. Luo et al., "Major factors controlling fracture development in the Middle Permian Lucaogou Formation tight oil reservoir, Junggar Basin, NW China," Journal of Asian Earth Sciences, vol. 146, pp. 279-295, 2017.

[32] F. Shihu, S. Yan, X. Huaimin, F. Ruidong, L. Loujun, and X. Xiucai, "Relationship between tectonic evolution and petroleum system formation-taking the Jimsar Sag of eastern Junggar Basin as an example," Petroleum Geology and Experiment, vol. 29, no. 2, p. 149, 2007.

[33] M. Wan, W. Yang, L. Liu, and J. Wang, “_Ductoagathoxylon jimsarensis_ gen. nov. et sp. nov., a gymnospermous stem from the Wuchiapingian (upper Permian) Wutonggou Formation in the Junggar Basin, northern Bogda Mountains, northwestern China," Review of Palaeobotany and Palynology, vol. 241, pp. 13-25, 2017.

[34] Y. Su, M. Zha, X. Ding et al., "Pore type and pore size distribution of tight reservoirs in the Permian Lucaogou Formation of the Jimsar Sag, Junggar Basin, NW China," Marine and Petroleum Geology, vol. 89, pp. 761-774, 2018.

[35] Y. Zhi, H. Lianhua, L. Senhu et al., "Geologic characteristics and exploration potential of tight oil and shale oil in Lucaogou Formation in Jimsar Sag," China Petroleum Exploration, vol. 23, no. 4, pp. 76-85, 2018.

[36] L. C. Fuzhong and L. M. Weihua, "The composition of the west section of the Piedmont fault in north margin of Bogda, Xinjiang, mountains and its activity in Holocene," Inland Earthquake, vol. 4, 1998.

[37] Z. Yan, L. Zhensheng, N. Feng, T. Xiaoli, and S. Yonghong, "Age, provenance and tectonic evolution of Late Paleozoic strata in Bogda Mountain, Xinjiang: evidence from detrital zircon U-Pb geochronology," Chinese Journal of Geology, vol. 50, no. 1, pp. 155-181, 2015.

[38] P. C. Hackley, N. Fishman, T. Wu, and G. Baugher, "Organic petrology and geochemistry of mudrocks from the lacustrine Lucaogou Formation, Santanghu Basin, northwest China: application to lake basin evolution," International Journal of Coal Geology, vol. 168, pp. 20-34, 2016.

[39] S. Tao, Y. Wang, D. Tang, D. Wu, H. Xu, and W. He, “Organic petrology of Fukang Permian Lucaogou formation oil shales at the northern foot of Bogda Mountain, Junggar Basin, China," International Journal of Coal Geology, vol. 99, pp. 27-34, 2012.

[40] R. Wang, W. Ding, Y. Zhang et al., "Analysis of developmental characteristics and dominant factors of fractures in Lower Cambrian marine shale reservoirs: a case study of Niutitang formation in Cen'gong block, southern China," Journal of Petroleum Science and Engineering, vol. 138, pp. 31-49, 2016.

[41] A. Ougier-Simonin, F. Renard, C. Boehm, and S. Vidal-Gilbert, "Microfracturing and microporosity in shales," EarthScience Reviews, vol. 162, pp. 198-226, 2016.

[42] J. Cui, "Oil transport in shale nanopores and micro-fractures: modeling and analysis," Journal of Petroleum Science and Engineering, vol. 178, pp. 640-648, 2019.

[43] R. Zimmerman and I. Main, "Hydromechanical behavior of fractured rocks," International Geophysics Series, vol. 89, pp. 363-422, 2004.

[44] B. L. Parker, J. A. Cherry, and S. W. Chapman, "Discrete fracture network approach for studying contamination in fractured rock," AQUA mundi, vol. 3, no. 2, pp. 101-116, 2012.

[45] D. J. Holcomb, "Memory, relaxation, and microfracturing in dilatant rock," Journal of Geophysical Research: Solid Earth, vol. 86, no. B7, pp. 6235-6248, 1981.

[46] C. H. Sondergeld and L. H. Estey, "Acoustic emission study of microfracturing during the cyclic loading of Westerly granite," Journal of Geophysical Research: Solid Earth, vol. 86, no. B4, pp. 2915-2924, 1981.

[47] L. Liu, S. Ma, J. Ma et al., “Temporal and spatial distribution of microfractures in granites of different structures under triaxial compression and its significance in seismology," Chinese Science Bulletin, vol. 44, no. 14, pp. 1321-1325, 1999.

[48] A. J. Mian, N. Driver, and P. T. Mativenga, "Chip formation in microscale milling and correlation with acoustic emission signal," The International Journal of Advanced Manufacturing Technology, vol. 56, no. 1-4, pp. 63-78, 2011.

[49] N. Golsanami, J. Sun, Y. Liu et al., "Distinguishing fractures from matrix pores based on the practical application of rock physics inversion and NMR data: a case study from an 
unconventional coal reservoir in China," Journal of Natural Gas Science and Engineering, vol. 65, pp. 145-167, 2019.

[50] T. Sun, W. Yan, H. Wang, N. Golsanami, and L. Zhang, "Developing a new NMR-based permeability model for fractured carbonate gas reservoirs," Journal of Natural Gas Science and Engineering, vol. 35, pp. 906-919, 2016.

[51] S. Chen, D. Tang, S. Tao, X. Ji, and H. Xu, "Fractal analysis of the dynamic variation in pore-fracture systems under the action of stress using a low-field NMR relaxation method: an experimental study of coals from western Guizhou in China," Journal of Petroleum Science and Engineering, vol. 173, pp. 617-629, 2019.

[52] K. Sun, S. Zhang, and L. Xin, "Impacts of bedding directions of shale gas reservoirs on hydraulically induced crack propagation," Natural Gas Industry B, vol. 3, no. 2, pp. 139-145, 2016.

[53] G. Borgia, V. Bortolotti, and P. Fantazzini, "Magnetic resonance relaxation-tomography to assess fractures induced in vugular carbonate cores," in SPE Annual Technical Conference and Exhibition, OnePetro, 1999.

[54] K. Bjørlykke and K. Høeg, "Effects of burial diagenesis on stresses, compaction and fluid flow in sedimentary basins," Marine and Petroleum Geology, vol. 14, no. 3, pp. 267-276, 1997.

[55] A. P. Lavenu, J. Lamarche, A. Gallois, and B. D. Gauthier, "Tectonic versus diagenetic origin of fractures in a naturally fractured carbonate reservoir analog (Nerthe anticline, southeastern France) tectonic vs. diagenetic fractures in a naturally fractured reservoir," AAPG bulletin, vol. 97, no. 12, pp. 2207-2232, 2013.

[56] M. R. Gross and Y. Eyal, "Throughgoing fractures in layered carbonate rocks," Geological Society of America Bulletin, vol. 119, no. 11-12, pp. 1387-1404, 2007.

[57] X. X. Wang, J. G. Hou, and S. H. Li, "Insight into the nanoscale pore structure of organic-rich shales in the Bakken Formation, USA," Journal of Petroleum Science and Engineering, vol. 191, article 107182, 2020.

[58] K. Zhang, J. Peng, W. Liu et al., "The role of deep geofluids in the enrichment of sedimentary organic matter: a case study of the Late Ordovician-Early Silurian in the upper Yangtze region and early Cambrian in the lower Yangtze region, south China," Geofluids, vol. 2020, 12 pages, 2020.

[59] K. Zhang, J. Peng, X. Wang et al., "Effect of organic maturity on shale gas genesis and pores development: a case study on marine shale in the upper Yangtze region, South China," Open Geosciences, vol. 12, no. 1, pp. 1617-1629, 2020.

[60] Y. Qi, Y. Ju, S. Meng et al., "Geological controls on high production of tight sandstone gas in Linxing Block, Eastern Ordos Basin, China," Acta Geologica Sinica-English Edition, vol. 94, no. 2, pp. 430-443, 2020.

[61] R. Resende, L. Lamas, J. Lemos, and R. Calçada, "Micromechanical modelling of stress waves in rock and rock fractures," Rock mechanics and rock Engineering, vol. 43, no. 6, pp. 741$761,2010$.

[62] N. Odling, P. Gillespie, B. Bourgine et al., "Variations in fracture system geometry and their implications for fluid flow in fractures hydrocarbon reservoirs," Petroleum Geoscience, vol. 5, no. 4, pp. 373-384, 1999.

[63] K.-B. Min, J. Rutqvist, C.-F. Tsang, and L. Jing, "Stress-dependent permeability of fractured rock masses: a numerical study," International Journal of Rock Mechanics and Mining Sciences, vol. 41, no. 7, pp. 1191-1210, 2004.
[64] A. Baghbanan and L. Jing, "Stress effects on permeability in a fractured rock mass with correlated fracture length and aperture," International Journal of Rock Mechanics and Mining Sciences, vol. 45, no. 8, pp. 1320-1334, 2008.

[65] M. Marder and S. Gross, "Origin of crack tip instabilities," Journal of the Mechanics and Physics of Solids, vol. 43, no. 1, pp. 1-48, 1995. 